\title{
Quarterly Progress Report on
}

\section{Tribopolymerization as an Anti-Wear Mechanism}

for the

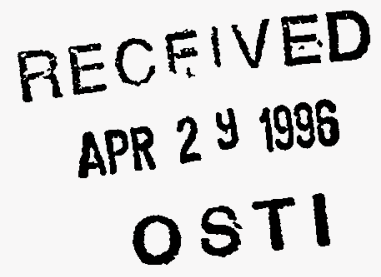

\author{
Energy-Related Inventions Program \\ Recommendation Number 584 \\ Grant No. DE-FG01-95-EE-15584 \\ U.S. Department of Energy \\ Washington, DC 20585
}

submitted by

\author{
Dr. Michael J. Furey \\ Principal Investigator \\ Department of Mechanical Engineering \\ Virginia Polytechnic Institute and State University \\ Blacksburg, Virginia 24061-0238
}

\section{DISCLAIMER}

This report was prepared as an account of work sponsored by an agency of the United States Government. Neither the United States Government nor any agency thereof, nor any of their employees, makes any warranty, express or implied, or assumes any legal liability or responsibility for the accuracy, completeness, or usefulness of any information, apparatus, product, or process disclosed, or represents that its use would not infringe privately owned rights. Reference herein to any specific commercial product, process, or service by trade name, trademark, manufacturer, or otherwise does not necessarily constitute or imply its endorsement, recommendation, or favoring by the United States Government or any agency thereof. The views and opinions of authors expressed herein do not necessarily state or reflect those of the United States Government or any agency thereof. 


\title{
Quarterly Progress Report on
}

\section{Tribopolymerization as an Anti-Wear Mechanism}

for the

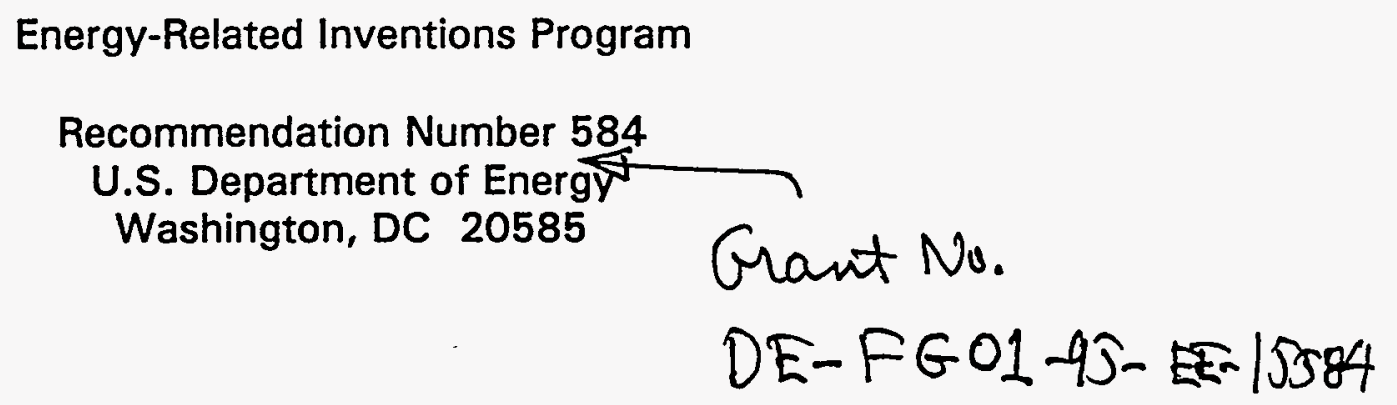

submitted by

\author{
Dr. Michael J. Furey \\ Principal Investigator \\ Department of Mechanical Engineering \\ Virginia Polytechnic Institute and State University \\ Blacksburg, Virginia 24061-0238
}




\section{SUMMARY}

During the first three months of 1996, progress on the Energy-Related Project was made in several different but connected areas. These included (a) establishing of load/velocity limits of selected monomers for ceramic lubrication, (b) the discovery of new and effective monomers designed for higher temperature anti-wear applications, (c) improvements and modifications of the high load/high speed pin-ondisk machine, (d) the initiation of related or spin-off projects designed to get our advanced technology into the marketplace, (e) the filing of three new patent applications, and (f) collaborative research with Dr. Kajdas -- the co-inventor with Dr. Furey -- on tribopolymerization as a novel and effective approach to the boundary lubrication of ceramics and steel. These and other elements of progress made during the first Quarter of 1996 are discussed briefly in the following paragraphs.

\section{PRIMARY OBJECTIVES}

The primary objective of this activity -- in keeping with the goals outlined in the DOE/ERIP proposal -- is to obtain the necessary data which would enhance, promote, and encourage the introduction of our advanced lubrication technology into the marketplace. This includes (a) defining specific but different applications, (b) establishing the limits or ranges of applied loads, speeds, and temperatures over which the concept of tribopolymerization would work in reducing wear and/or friction, (c) continuing in our efforts to understand the film-forming process (this relates to (b) above), using this knowledge to develop new and even more effective additives, and (d) exploring possible connections with private and investment companies for the licensing and marketing of products which will reduce friction and wear in a variety of applications.

\section{PERSONNEL INVOLVED}

The personnel involved in this research during the first three months of 1996 consisted of (a) Dr. Michael J. Furey as Principal Investigator, (b) Mr. Jeff Valentino, Graduate Research Assistant, and (c) Dr. Czeslaw Kajdas who traveled from Poland and spent the month of February at Virginia Tech in collaborative research in tribopolymerization on several different but related projects, including the DOE/ERIP. Although Dr. Kajdas was not paid by the ERIP project, he contributed significantly to our research in this area.

\section{TEST DEVICES}

The operation and reproducability of the high-load/high-speed pin-on-disk machine were improved by making modifications to the device as well as procedure. One problem was due excessive vibration at certain speeds caused by small differences in the alignment of the rotating disk assembly. Initial attempts to modify the device for vapor-phase lubrication at high temperatures were only partially successful. A quotation for a high-temperature, vapor-phase pin-on-disk machine was obtained from Teretechnology in Radom, Poland. Although not absolutely essential 
for the DOE/ERIP research, such a device would be very useful and highly desirable. The acquisition of additional funds to couple with this research for the advanced hightemperature machine is being explored. In the meantime, we have designed a simple heating chamber unit which would permit higher temperature operation of our existing pin-on-disk device; this will not have vapor-phase capabilities, however.

\section{NEW AND PROMISING MONOMER CLASSES INVESTIGATED}

Our patent on ceramic lubrication which was issued in April 1995, covers the use of a wide range of addition-type (e.g., vinyl) monomers as a method to reduce ceramic wear. These monomers may tend to polymerize at lower temperatures on rubbing surfaces or to form polymers which cannot withstand higher surface temperatures (e.g., $300^{\circ} \mathrm{C}$ and higher). Therefore, we have selected and synthesized several new monomers which are designed for high-temperature applications. These are chiefly of the condensation-type and may contain amine groups for forming polyamides or aromatic rings for greater thermal stability. Since patent disclosures on specific compounds and combinations of compounds have not yet been formally transmitted to Virginia Tech Intellectual Properties, we are not at liberty at this point to disclose exact chemical structures. However, four of the new additives reduced ceramic wear in alumina-on-alumina tests by over $98 \%$ even at concentrations much less than $1 \%$. This is exciting and opens the door to new classes of compounds we believe will be more effective in reducing friction and wear at higher temperatures. The compounds have limited solubility in hydrocarbons (e.g., mineral oils) but nevertheless are effective even when low initial concentration fluids are filtered.

\section{SURFACE TEMPERATURE MODELING}

A general and extremely useful boundary element model has been developed by my colleague, Dr. Brian Vick, as part of previous funding of a joint theoretical/experimental study funded by the National Science foundation. We believe that the actual surface temperatures produced by friction (e.g., with ceramic-onceramic or ceramic-on-steel) are important in initiating surface polymerization. Plans to adapt the theoretical model to a more user-friendly version are underway. This can be used in our calculations of surface temperatures produced in sliding contact under various conditions and in diverse tribological systems.

\section{PATENTS AND PATENT APPLICATIONS}

Our basic patent on this method of ceramic lubrication was issued in April 1995. It is U.S. Patent 5,407,601, "Compositions for Reducing Wear on Ceramic Surfaces," Inventors Michael J. Furey and Czeslaw Kajdas. A copy is attached for your information.

In addition, three new applications relating to our concept and applications were filed in February 1996. They cover the following areas: (1) vapor-phase lubrication; (2) lubrication of ceramic tools for machining and cutting; and (3) lubricating compositions for steel, alloys, and ceramics. 


\section{PUBLICATIONS, LECTURES}

A paper on the concept and applications of tribopolymerization was presented at the 10th International Colloquium on Tribology -- Solving Friction and Wear Problems, held at Technische Akademie Esslingen, Germany, 9-11 January 1995. The paper, "Action Mechanism of Selected Vinyl Monomers Under Boundary Lubrication of Alumina-on-Alumina System," was co-authored by M. J. Furey, C. Kajdas, R. Kempinski, and B. S. Tripathy (Vol. 3, pp. 1847-1863). A version of this paper will be published in "Lubrication Science." Other papers are planned.

\section{TRIAD INVESTORS, INC.}

Agreements have been signed between Virginia Tech Intellectual Properties, the University's Office of Sponsored Research, and Triad Investors, Inc. to help support and push for the licensing and marketing of our advanced lubrication technology. Three connected research projects are in progress. They involve (1) the use of our ashless lubricity additives in fuels for 2-stroke gasoline engines to achieve lubrication with reduced emissions, (2) machining/cutting research with ceramic tools, and (3) vapor-phase lubrication.

\section{OTHER INDUSTRIAL CONTACTS}

In January, a proposal was made to NASA under the small business program (STTR) which involves collaboration with AMW Cuyuna, Inc. -- a small aircraft engine manufacturer in South Carolina -- and our Tribology Laboratory at Virginia Tech. The idea is to develop a light-weight carbon composite, 2-stroke Diesel engine for aircraft use -- thus improving fuel efficiency. Since the carbon composite piston and rings degrade at high temperatures, they are coated with silicon carbide ceramic -- a system which we believe will respond to our lubrication approach. We are waiting to hear about Phase I funding.

Industrial contacts have been made with other companies, including Tecumseh Engines in Wisconsin. A recent visit by eight Tecumseh representatives to our Department resulted in considerable interest in our lubrication approach. Dr. Furey plans to visit Tecumseh in the near future to discuss areas of collaboration.

\section{NEWS ITEMS AND PUBLICITY}

Copies of recent news releases and articles on our research on tribopolymerization are attached for your information. Although they deal chiefly with the collaboration between Dr. Furey and Dr. Kajdas over a 10-year period on their concept of tribopolymerization, the recognition by the DOE Energy-Related Inventions Program played an important role in stimulating our research and in making contacts for marketing and industrial applications. 


\section{FUTURE WORK}

Research using the pin-on-disk machine under more severe conditions and with new monomers will continue. During the summer, we will be joined by our Polish researchers -- Drs. Kajdas and Kempinski. The summer activity will be rather intense and will include:

(1) Examination of all experimental results, paying special attention to limiting factors for effectiveness of selected anti-wear compounds;

(2) FTIR studies of ceramic surfaces by Dr. Kempinski to help us to better understand the protective film-forming process;

(3) Use of CHEM-X computer program to model additive/surface interactions;

(4) Surface temperature calculating and mapping;

(5) Continued acquisition of new data for patent applications;

(6) Working with Triad Investors and industrial firms to make specific inroads in applications, licensing, and marketing;

(7) Analysis of all data, including industrial feedback to determine their significance, most promising applications, and additional work needed;

(8) Decision on a high-temperature, vapor-phase pin-on-disk machine for a wide range of tribological studies under diverse conditions;

(9) Preparation of additional papers for publications;

(10) Possible submission of a new DOE/ERIP proposal. 
[54] COMPOSITIONS FOR REDUCING WEAR ON CERAMIC SURFACES

[75] Inventors: Michael J. Furey, Blacksburg, Va; Czeslar Kajdas, Plock, Poland

[73] Assignee: Center For Innovative Technology, Herndon, $\mathrm{Va}$.

[21] Appl. No.: 22,741

[22] Filed: Feb. 17, 1993

Related U.S. Application Data

[63] Continuation of Ser. No. 604,771, Oct. 26, 1990, abandoned.

[51] Int. Cl.6 C10M.105/68; C10M 105/80

[52] U.S. Cl. 252/51.5 A; 252/25; $252 / 49.7 ; 252 / 52 \mathrm{R} ; 252 / 56 \mathrm{D} ; 252 / 56 \mathrm{~S}$; $501 / 134 ; 501 / 153 ; 501 / 154$

[58] Field of Search ................ 252/56 R, $56 \mathrm{D}, 56 \mathrm{~S}$, $252 / 52 \mathrm{R}, 12,12.2,515 \mathrm{~A}, 286,49.9,49.5$; S85/10, 12, 18; 106/46; 501/134, 153, 154

[56]

References Cited

\section{U.S. PATENT DOCUMENTS}

$3,114,708 \quad 12 / 1963$ Morway et al. $252 / 12$

$3,180,832$ 4/1965 Furey

3,273,981 9/1966 Furey $252 / 56 \mathrm{~S}$

3,287,273 11/1966 Furey et al. ............................... 252/57

$3,429,817 \quad 2 / 1969$ Furey et al.

3,516,933 6/1970 Andrews ............................... 252/12

3,827,892 8/1973 McCauley ............................... 252/12

4,462,920 7/1984 Synder et al. ....................... 252/49.5

$4,469,611 \quad 9 / 1984$ Synder et al. ......................... 252/49.5

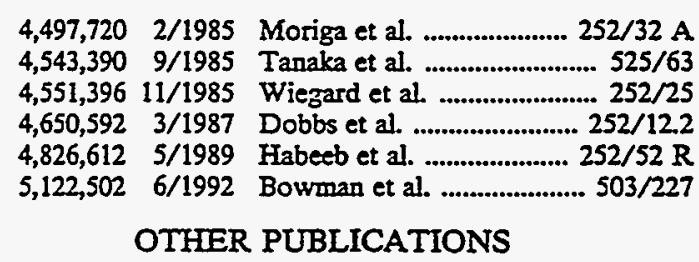

Furey, "The Formation of Polymeric Fils Directly on Rubbing Surfaces to Reduce Wear", Wear, vol. 26, (1973), pp. 369-392 (no month).

Furey, "The In Situ Formation of Polymeric Films on Rubbing Surfaces", Proc. Int. Collog;; Polymers and Lubrication, Brest, Centre National de la Recherche Scientifique, Paric, No. 233 (1975), pp. 393-404 (no month).

Furey et al., "Thermal and Catalytic Effects on Tribopolymerization as a New Boundary Lubrication Mechanism", Wear, vol. 136 (1990), pp. 85-97. (no month).

Primary Examiner-Margaret Medley Attormey, Agent, or Firm - Whitham, Curtis, Whitham \& McGinn

[57]

ABSTRACT

Fluid compositions comprised of a monomer constituent dissolved in a carrier fluid, where the monomer constituent is capable of forming a polymer film directly on rubbing surfaces but is not polymerized in solution, have been found to be effective for reducing ceramic wear.

8 Claims, 15 Draring Sheets
Additive in Hexadecome

For Alumina-on-

Alumina System

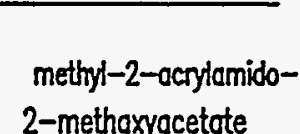

2-methaxyacetote

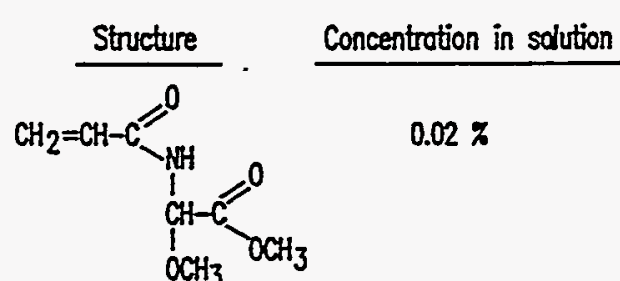

$0.10 \%$

$1.00 \%$

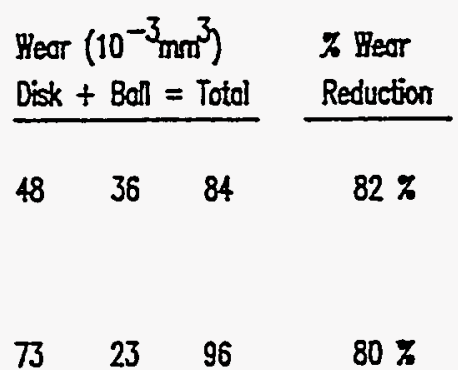

$85 \quad 40 \quad 125$

$73 \%$ 


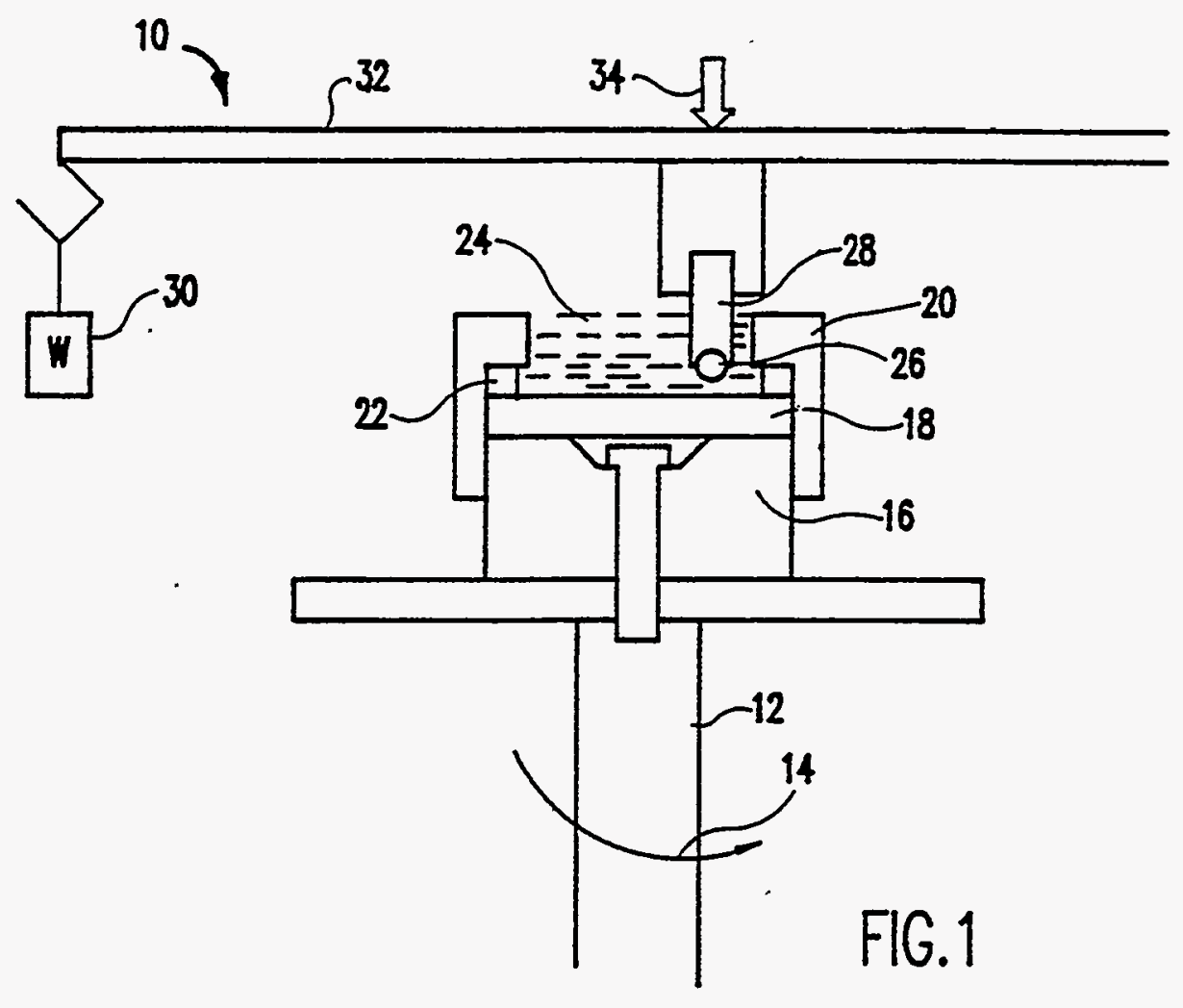

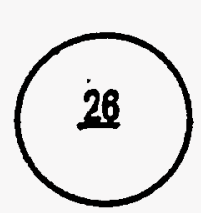

FIG.2A

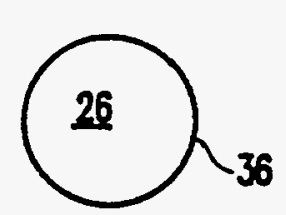

FIG.2B

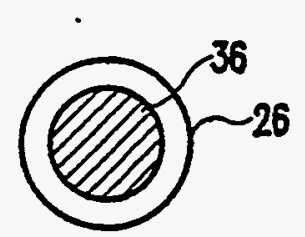

FIG.3

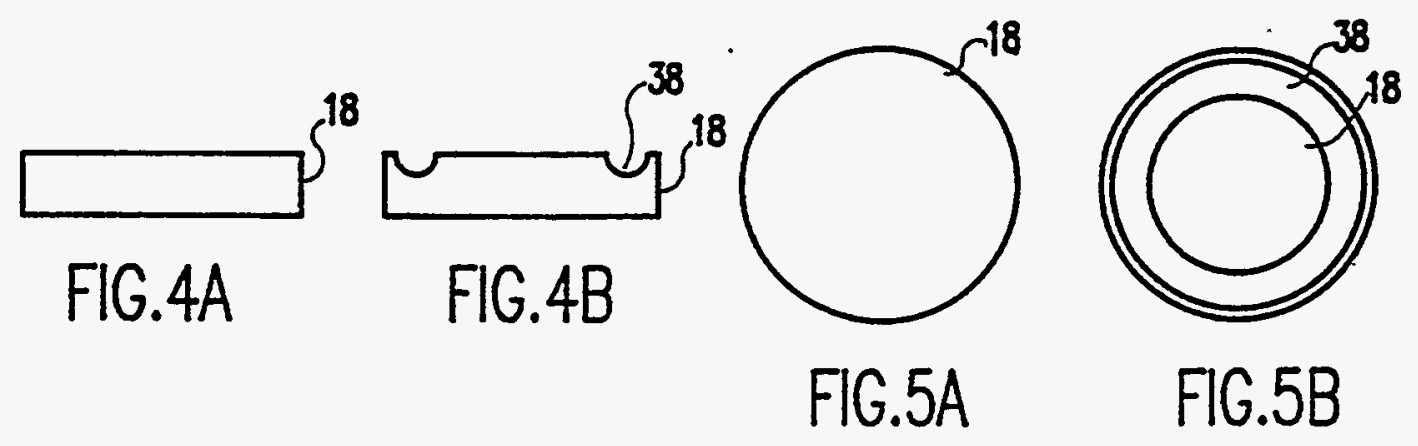




\begin{tabular}{|c|c|c|c|c|c|}
\hline $\begin{array}{l}\text { Additive in Hexadecane } \\
\text { For Alumina-on- } \\
\text { Alumina System }\end{array}$ & $\begin{array}{l}\text { Structure } \\
\mathrm{CH}_{2}=\mathrm{CHX} \text { (where Xis) }\end{array}$ & $\begin{array}{l}\text { Wear } \\
\text { Disk }\end{array}$ & $\begin{array}{l}10^{-} \\
\text {Ball }\end{array}$ & $\begin{array}{l}\left.\mathrm{nm}^{3}\right) \\
=\text { Total }\end{array}$ & $\begin{array}{l}\text { \% Wear } \\
\text { Reduction }\end{array}$ \\
\hline 1-dodecene & $-\left(\mathrm{CH}_{2}\right)_{9} \mathrm{CH}_{3}$ & 190 & 57 & 247 & $47 \%$ \\
\hline 1-tetradecene & $-\left(\mathrm{CH}_{2}\right)_{11} \mathrm{CH}_{3}$ & 343 & 150 & 493 & [5\% INCREASE \\
\hline 1-hexadececne & $-\left(\mathrm{CH}_{2}\right)_{13} \mathrm{CH}_{3}$ & 170 & 93 & 263 & $44 \%$ \\
\hline 1-octadecene & $-\left(\mathrm{CH}_{2}\right)_{15} \mathrm{CH}_{3}$ & 157 & 67 & 224 & $48 \%$ \\
\hline 1-eicosene & $-\left(\mathrm{CH}_{2}\right)_{17} \mathrm{CH}_{3}$ & - & - & [est. 440] & No Effect \\
\hline \multicolumn{6}{|c|}{$\begin{array}{l}* \text { at } 300 \mathrm{~m} \text {, very noisy } \\
\left.\qquad \begin{array}{c}D=168, P=96, D \times P=2640300 \mathrm{~m} . \\
\text { EST } 4400500 \mathrm{~m}\end{array}\right\}\end{array}$} \\
\hline
\end{tabular}

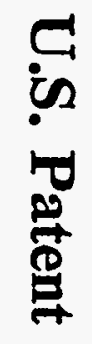

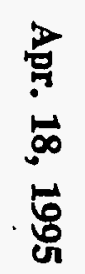

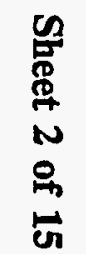




\begin{tabular}{|c|c|c|c|c|c|}
\hline $\begin{array}{l}\text { Additive in Hexadecane } \\
\text { For Alumina-on- } \\
\text { Alumina System } \\
\end{array}$ & $\begin{array}{l}\text { Structure } \\
\mathrm{CH}_{2}=\mathrm{CHX} \text { (where Xis) }\end{array}$ & $\begin{array}{l}\text { Wear } \\
\text { Disk }\end{array}$ & $\begin{array}{l}10^{-} \\
\text {Ball }\end{array}$ & & $\begin{array}{l}\% \text { Wear } \\
\text { Reduction }\end{array}$ \\
\hline Styrene & & 138 & 95 & 233 & $50 \%$ \\
\hline 4-methyl styrene & & 220 & 83 & 303 & $35 \%$ \\
\hline 4-vinylbiphenyl & & 125 & 88 & 213 & $55 \%$ \\
\hline 2-vinyinaphthalene & & 176 & 70 & 216 & $48 \%$ \\
\hline 9-vinylanthracene & & 230 & 97 & 327 & $30 \%$ \\
\hline
\end{tabular}




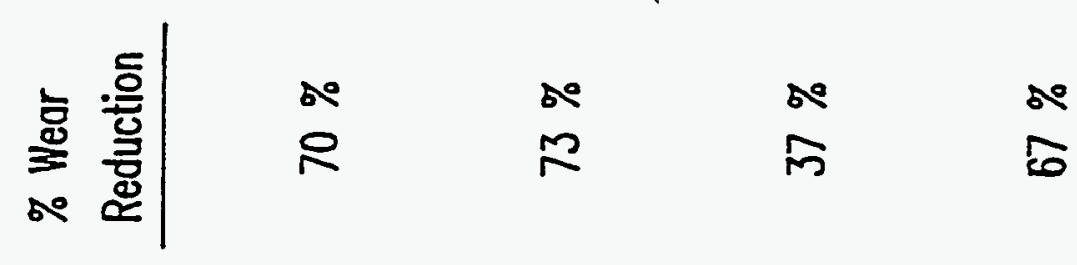

\begin{tabular}{|c|c|c|c|}
\hline m 흥 & 里 & $\stackrel{\mathscr{N}}{\mathrm{N}}$ & ह્ণ \\
\hline $\begin{array}{ll}1 & \overline{0} \\
0 & 0 \\
+\end{array}$ & $\stackrel{2}{q}$ & $\overline{6}$ & $\approx$ \\
\hline$\stackrel{\text { 总 }}{\underline{\underline{0}}}$ & ' & & $\mathbb{N}$ \\
\hline
\end{tabular}
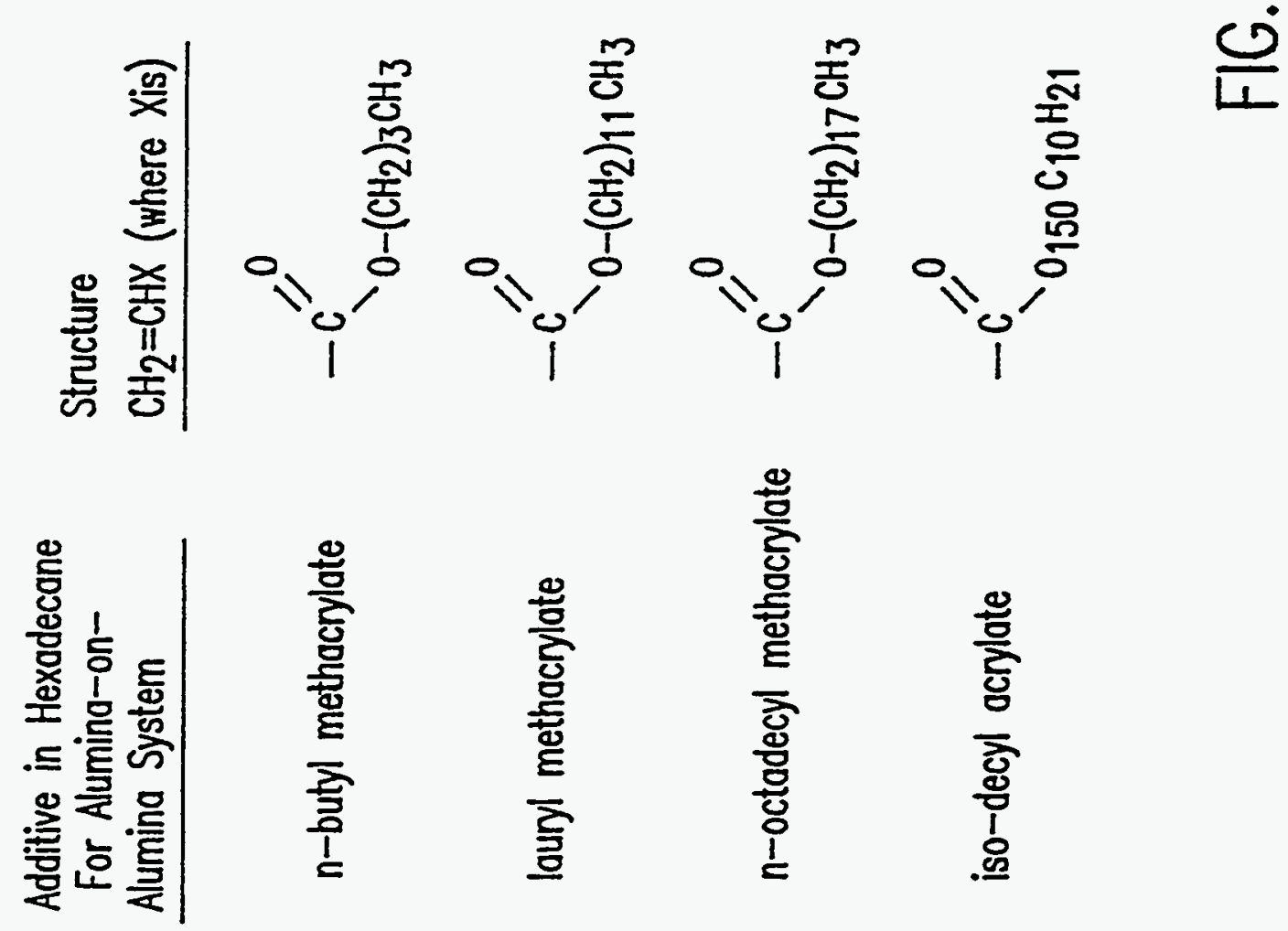

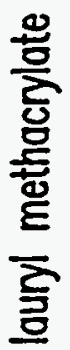

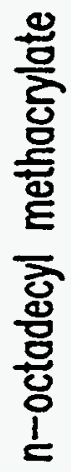

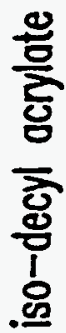




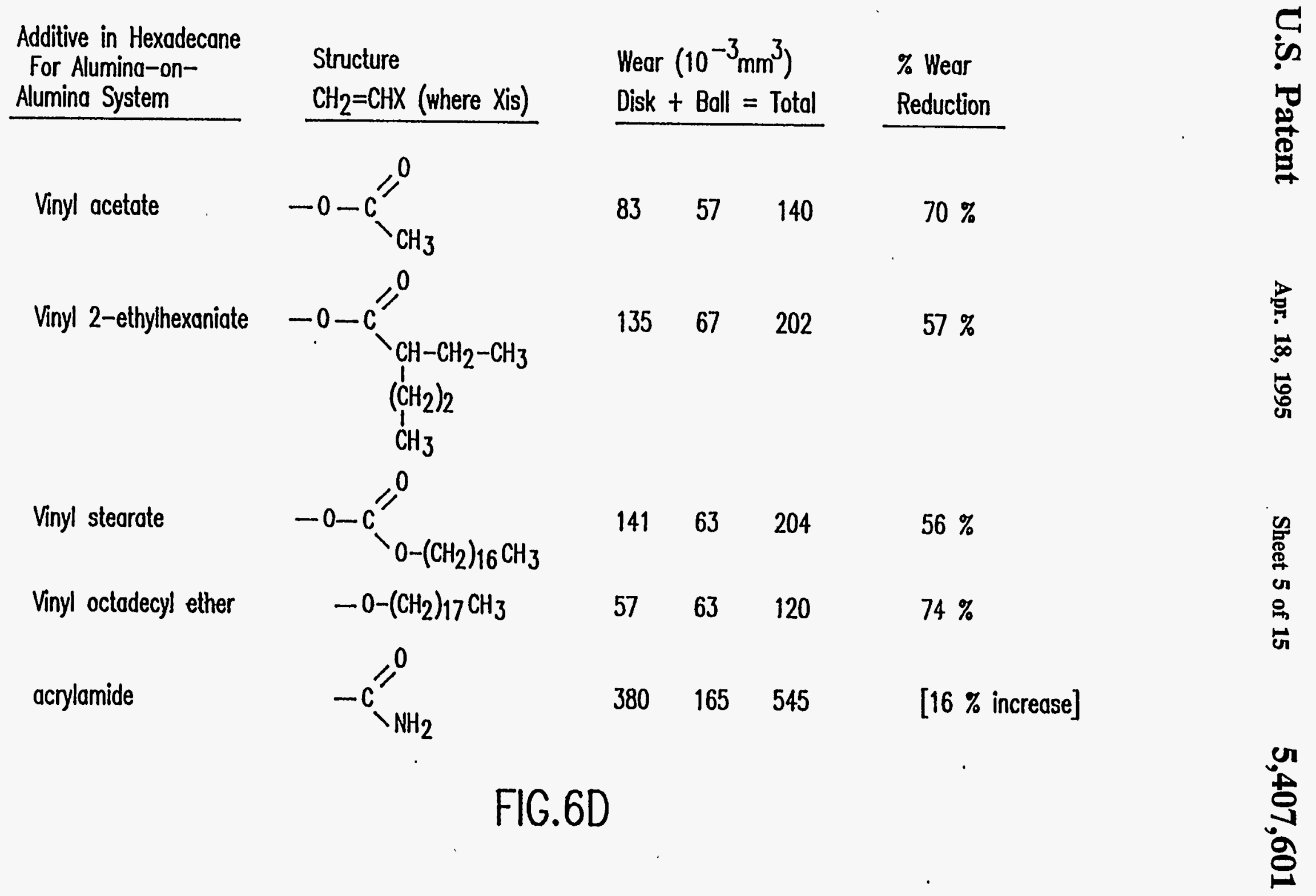


Additive in Hexadecane

For Alumina-on-

Alumino System

Vinyl cycleoctane
$\mathrm{CH}_{2}-\mathrm{CH}_{2}-\mathrm{CH}_{2}$
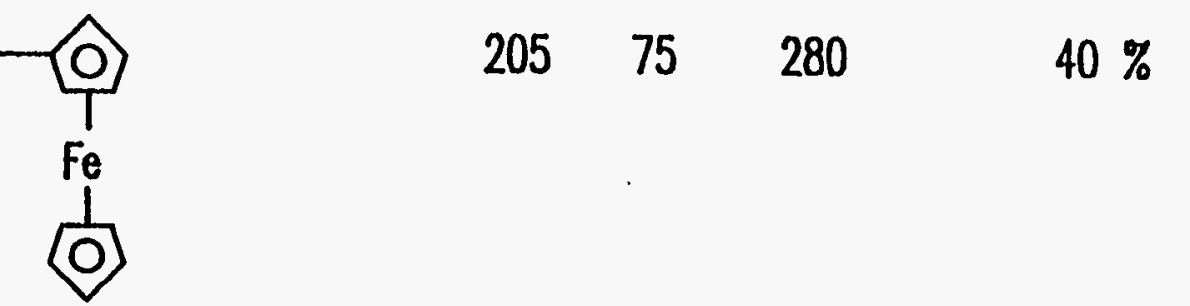

$$
\text { Wear }\left(10^{-3} \mathrm{~mm}^{3}\right)
$$

$\%$ Wear

Disk + Ball $=$ Total

188

106

294

$37 \%$

0
0
0
0
0
0
0
0

害

$\begin{array}{llll}205 & 75 & 280 & 40 \%\end{array}$

Vinyl ferrocene

FIG.6E 
Additive in Hexadecane

For Alumina-on-

Alumina System

Structure

Wear $\left(10^{-3} \mathrm{~mm}^{3}\right)$

$\%$ Wear

$\mathrm{CH}_{2}=\mathrm{CH}-\mathrm{X}-\mathrm{CH}_{2}$ (where Xis) $\quad$ Disk + Ball = Total Reduction

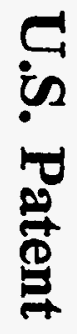

diallyl phthalate

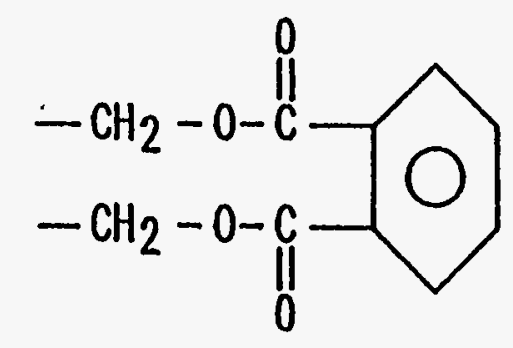

$147 \quad 57 \quad 204$

$57 \%$

diallyl succinate

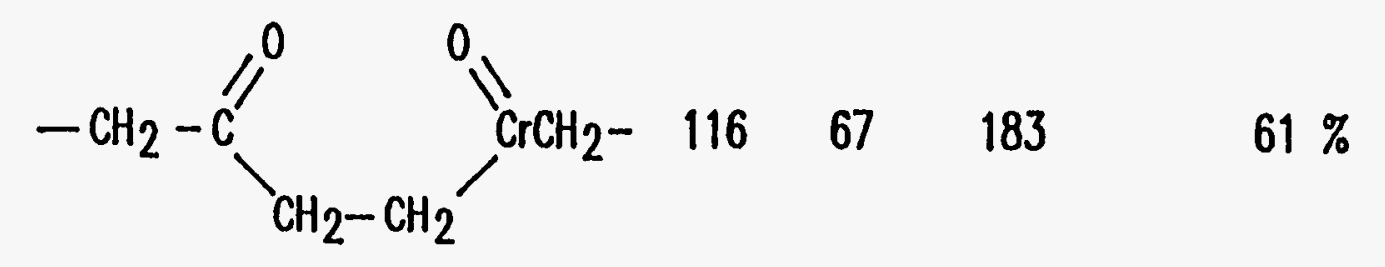

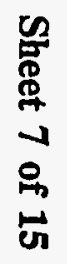

FIG.6F 


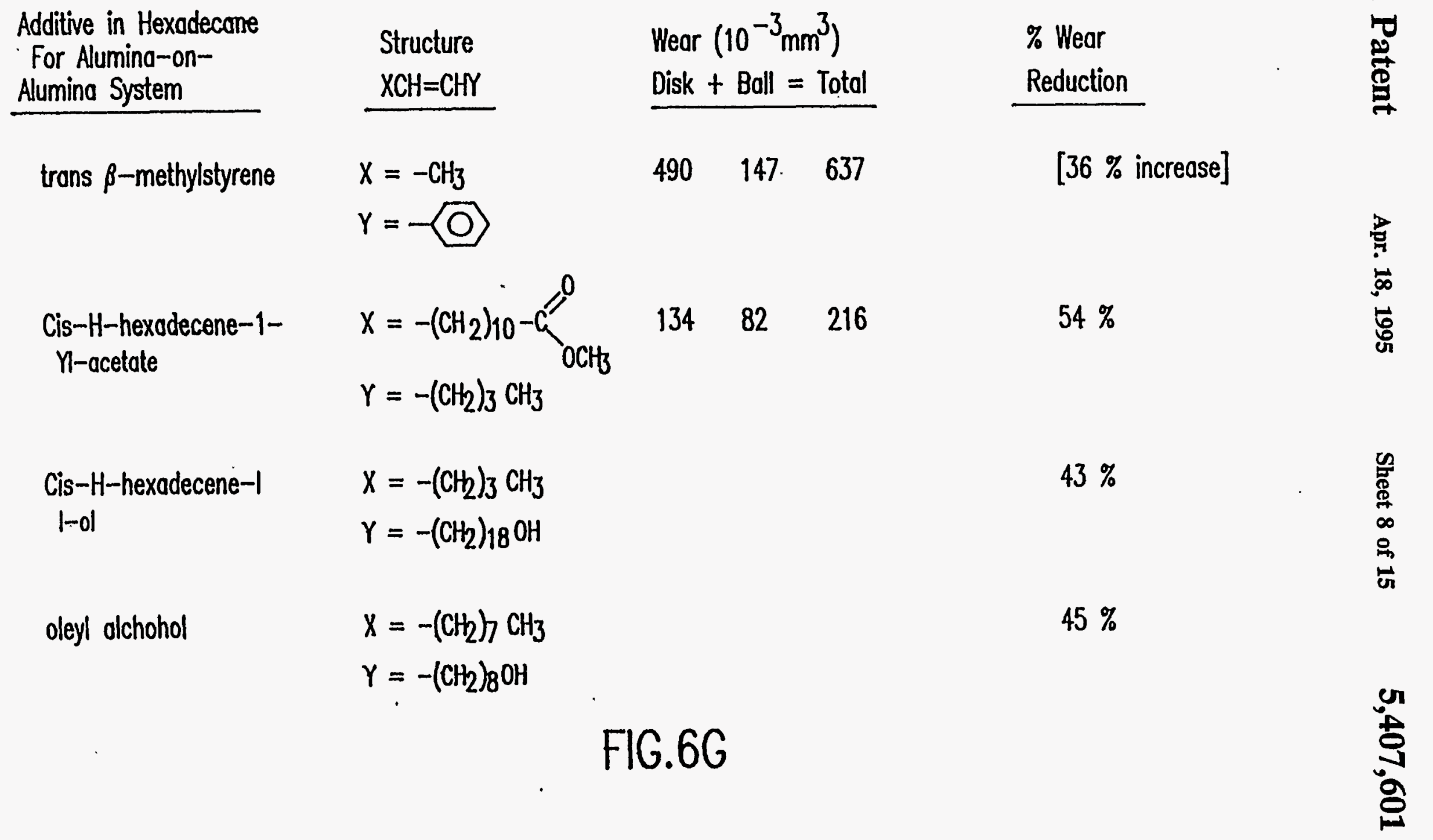


Additive in Hexadecone For Alumina-on-

Alumina System

I, 1-diphenylethylene

$a-$ methylstyrene

methacrylamide
Structure

$\mathrm{CH}_{2}=\mathrm{CXY}$

$X=-0$
$Y=-0$

$\mathrm{X}=-\mathrm{CH}_{3}$

$Y=0$

$x=-\sum_{N H_{2}}^{O}$
$Y=-\mathrm{CH}_{3}$
Wear $\left(10^{-3} \mathrm{~mm}^{3}\right)$

Disk + Ball = Total

$\begin{array}{lll}196 & 96 & 292\end{array}$

$230 \quad 116 \quad 346$

$\begin{array}{lll}330 & 151 & 481\end{array}$
$26 \%$

$\%$ Wear

Reduction

$38 \%$

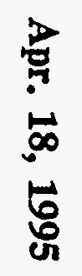

[ $2 \%$ increase] No significant effect

\section{$\mathrm{FIG.6H}$}


Additive in Hexadecone

For Alumina-on-

Alumina System

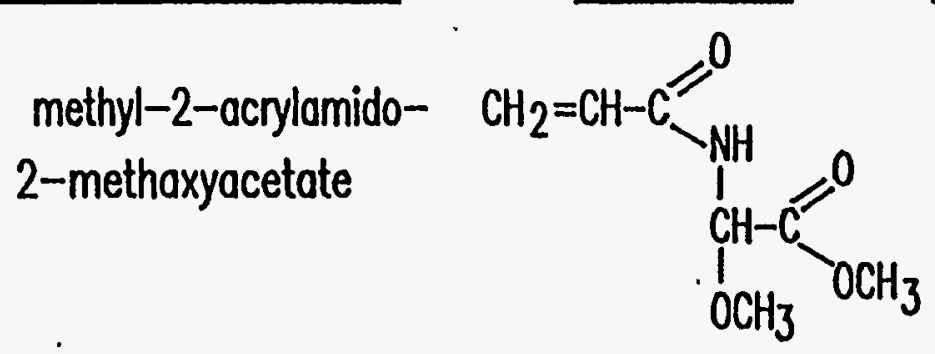

Wear $\left(10^{-3} \mathrm{~mm}^{3}\right) \quad \%$ Wear

Disk + Ball $=$ Total $\quad$ Reduction

$\begin{array}{llll}48 & 36 & 84 & 82 \%\end{array}$

$\begin{array}{llll}73 & 23 & 96 & 80 \%\end{array}$

$\begin{array}{llll}85 & 40 & 125 & 73 \%\end{array}$

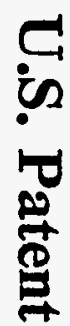

$0.02 \%$

$0.10 \%$

$1.00 \%$

FIG.7

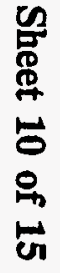

en
है
ह
ह 


\begin{tabular}{|c|c|c|c|c|c|c|}
\hline 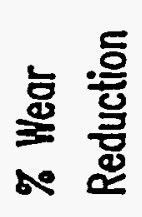 & 1 & 1 & 1 & $\begin{array}{l}\text { ஷ̊ } \\
\stackrel{2}{\circ}\end{array}$ & $\begin{array}{l}\not \\
\infty\end{array}$ & $\begin{array}{l}\ddot{0} \\
\dot{q}\end{array}$ \\
\hline 辰 & $\frac{9}{ \pm}$ & 요 & 䄱 & Фิ & $\stackrel{20}{n}$ & $\stackrel{\sim}{\mathbb{Z}}$ \\
\hline io & 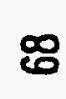 & $\mathbb{\infty}$ & $\stackrel{2}{\circ}$ & กี & $\Sigma$ & 4 \\
\hline 总 & $\bar{\infty}$ & ฐ & 屌 & $\notin$ & $\mathscr{\infty}$ & 包 \\
\hline 䇏 & is & 으 & నี & in & 운 & శి \\
\hline
\end{tabular}
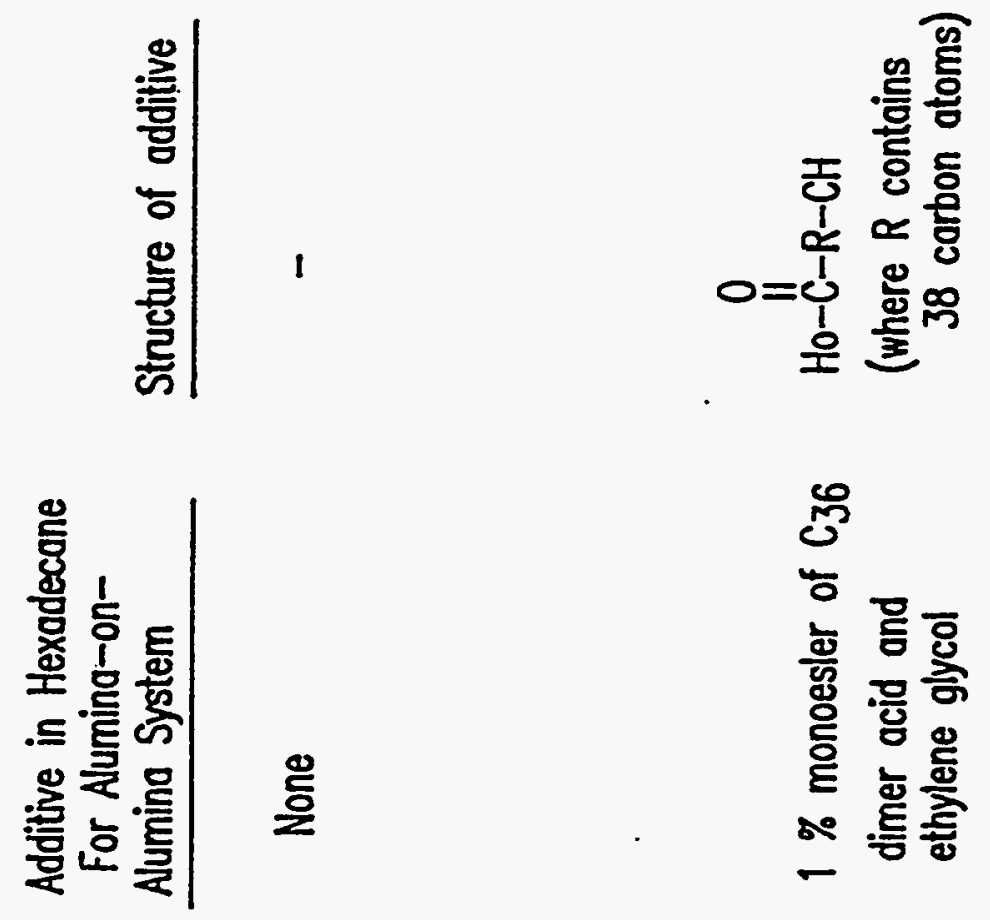


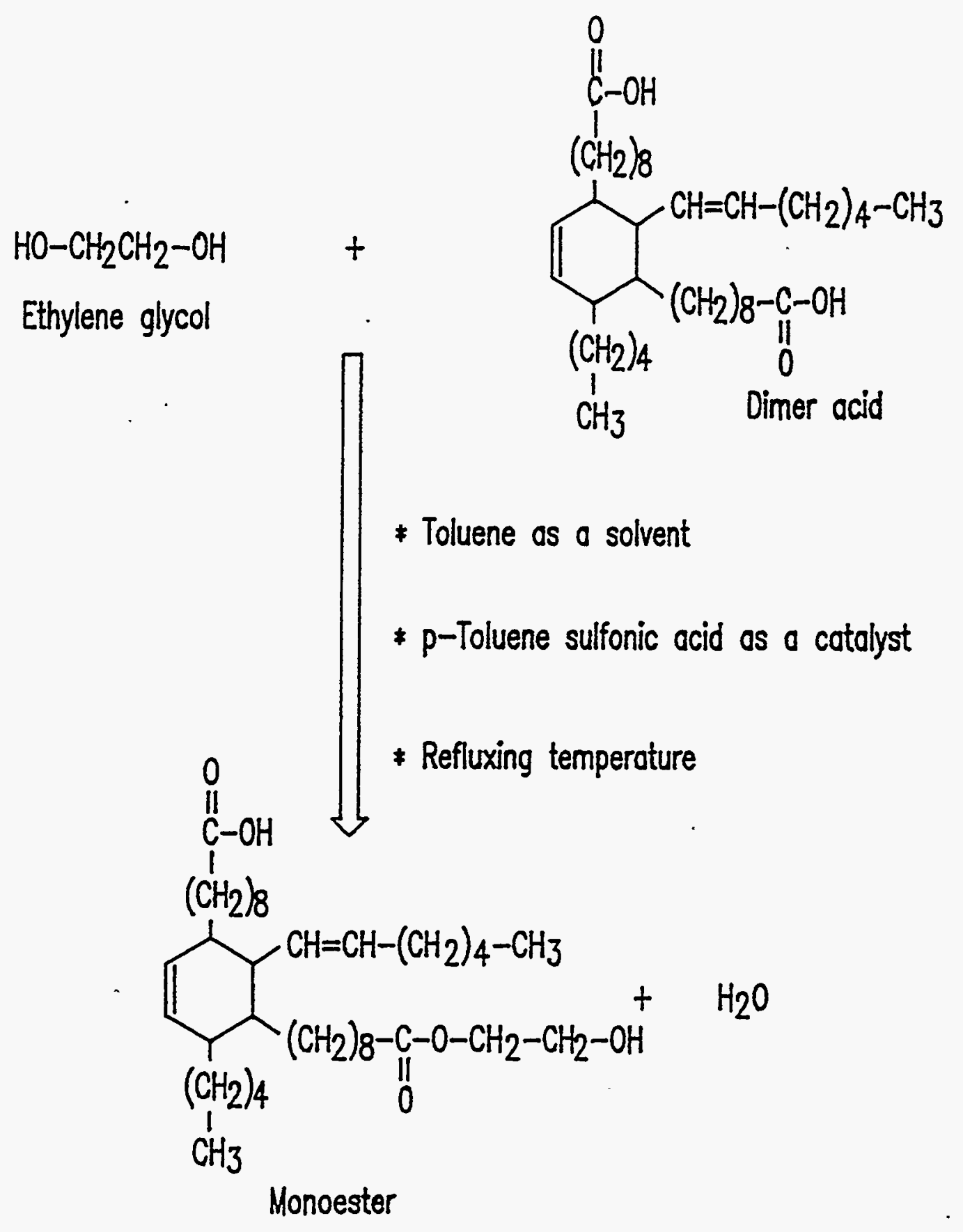

FIG.8B 
ADDTINE IN HEXADECANE

FOR ZIRCONA-ON-

ZIRCONIA SYSTEN
AVERAGE

BALI YEAR

$\left(10^{-3} \mathrm{~mm}^{3}\right)$
\% MEAR

REDUCTION
1\% $\mathrm{C}_{36}$ dimer acid/

ethylene glycol monoester

$1 \%$ amino undecanoic acid

$1 \%$ 1-dodecene

$1 \%$ 1-elcosene

1\% lauryl methocrylate

$1 \%$ diallyl phthalate

$1 \%$ vinyl octadecyl ether
1.11

36

1.23

29

1.41

18

1.39

20

0.95

45

1.11

36

0.95

45

FIG.9 


\section{ADOTIME IN \\ HEXADECANE FOR \\ $\mathrm{Si}_{3} \mathrm{~N}_{4}$-ON-SizN4 SYSTEN}

$1 \%$ lauryl methacrylate

$1 \%$ diallyl phtholate

$1 \%$ 1-dodecene

1\% 11-amino undecanoic acid

1\% $\mathrm{C}_{36}$ dimer acid/

ethylene glycol monoester

$1 \%$ methyl-2-acryloamido-

2-methoxy acetate

vinyl octadecyl ether

vinyl acetate

styrene

\section{AVERAGE \\ BALL TEAR \\ $\left(10^{-3} \mathrm{~mm}^{3}\right)$}

F VEAR

REDUCTION
1.113

0.549

1.013

0.591

0.316

65

No effect

No effect

No effect 
Effect of $\mathrm{C}_{36}$ Dimer Acid/Ethylene Glycol Monoester and Applied Load on Fretting Wear

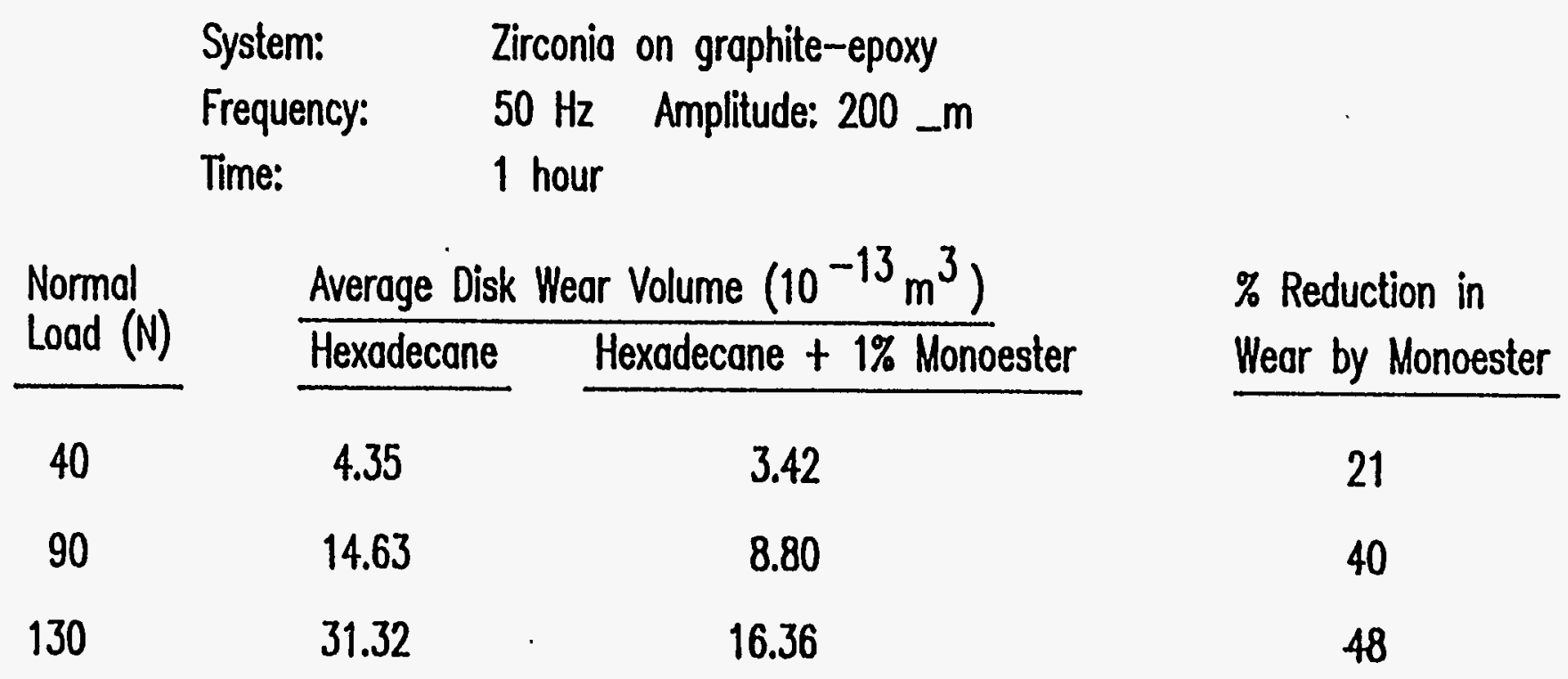

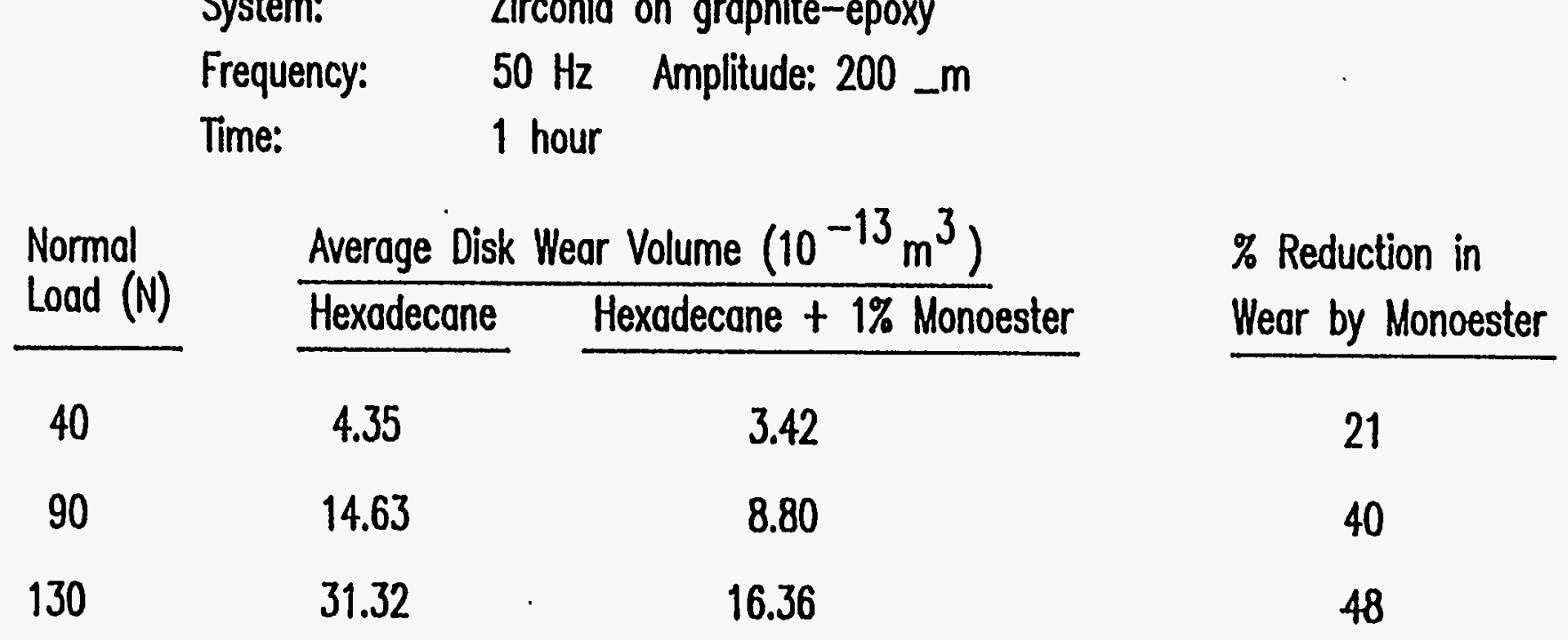

FIG.11

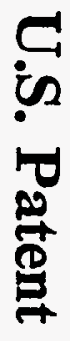

总

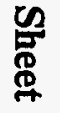

它

용

它

㫄 


\section{COMPOSITIONS FOR REDUCING WEAR ON CERAMIC SURFACES}

\section{CROSS-REFERENCE TO RELATED APPLICATIONS}

This patent application is a continuation of the patent application having Ser. No. 07/604,771, filed Oct. 26, 1990, now abandoned. The complete contents of the patent application having Ser. No. 07/604,771 is incorporated by reference.

\section{BACKGROUND OF THE INVENTION}

\section{Field of the Invention}

The subject invention is generally directed to antiwear additives and fluid compositions containing antiwear additives which can effectively reduce wear in ceramic systems and, more particularly, to utilizing monomer compounds that are capable of polymerizing directly on rubbing surfaces under tribological conditions and function as anti-wear additives.

2. Description of the Prior Art

Recently there has been much interest in using ceramic materials in a wide variety of applications which traditionally have utilized metals. Ceramic materials 25 have several advantageous engineering properties. For example, ceramics generally have high hardness, high melting points, low density, low thermal expansion, corrosion resistance, and high resistance to thermal and chemical stresses. Particular ceramic materials which are currently being used or considered for use in tribological applications include the following: alumina (aluminum oxide or $\mathrm{Al}_{2} \mathrm{O}_{3}$ ), zirconia (zirconium oxide or $\mathrm{ZrO}_{2}$ ), silicon nitride $\left(\mathrm{Si}_{3} \mathrm{~N}_{4}\right)$, silicon carbide (SIC), boron nitride $(B N)$, aluminum nitride ( $A 1 N$ ), boron 35 carbide $\left(\mathrm{B}_{4} \mathrm{C}\right)$, and beryllia (beryllium oxide $\mathrm{BeO}$ ). It is envisioned that ceramics will provide useful solutions in advanced propulsion systems, low heat rejection engines, aerospace bearings, turbomachinery, adiabatic diesel engines, high speed roller bearings in gas turbine 40 engines, as well as a wide variety of other systems.

Wear has been defined as the progressive loss of a substance from the operating surface of a body as a result of relative motion at the surface of the body (see, Furey, "Tribology", Encyclopedia of Materials Science \& 45 Engineering, Pergamon Press, Oxford, pp. 5145-5157, 1986). When ceramic elements rub together or when a ceramic element rubs against an element made from a different material such as a metal or composite element, wear occurs. The rate of wear tends to increase under 50 harsh temperature and pressure conditions which exist inside ceramic engines, propulsion systems, and the like. In addition to limiting the useful life of the part in which the ceramic is used, wear of ceramics can be costly because the ceramic materials themselves are expensive to produce.

In the prior art, basically four different approaches to lubricating ceramics have been investigated. In the first approach, various materials such as oils, additives, polymers, solid lubricants, and soaps, have been incorpo- 60 rated into ceramics prior to manufacturing the ceramic element so that the resulting ceramic element has a "self-lubricating" property. Since this approach requires incorporation of the materials into the ceramic prior to formation of the ceramic element, it is not use- 65 ful as a lubrication scheme for lubricating existing stateof-the-art bearings or other components. Moreover, when incorporating the additives into the ceramic, the
2

physical changes to the ceramic produced relative to the ceramic without the additives must be considered. In the second approach, the ceramic elements have been subjected to various surface treatments such as ion

5 sputtering and implantation, or the ceramic elements have had various coatings applied thereto such as metal films, solid lubricants, and polymer films. A particular disadvantage of these surface treatments and film coatings is that they are themselves removed by wear. 10 Hence, surface treatments and film coatings have a finite life and are non-replenishing. In a third approach, conventional soluble anti-wear additives have been added to a fluid carrier (e.g., mineral oil). This approach typically requires a specific reaction with a metal sur5 face to form a low shear film such as iron phosphate, iron sulfide, or iron compounds of unknown composition; therefore, this approach would not be expected to be applicable to the less chemically reactive ceramic materials. In the fourth approach, dispersed solid lubricants such as graphite or molybdenum disulfide in oils have been applied to the ceramic surface. These dispersions have not yielded satisfactory results for a variety of reasons including the fact that high concentrations of the dispersion are generally needed and settling of the dispersion and filter plugging occurs.

In short, none of the four approaches discussed above have been very successful in lubricating ceramics and a new approach to reducing ceramic wear which overcomes the difficulties of the prior art would be most beneficial.

\section{SUMMMARY OF THE INVENTION}

It is therefore an object of the present invention to provide novel compositions for protecting ceramic components from excessive wear.

It is another object of the present invention to use monomer compounds that are capable of polymerizing under tribological conditions as anti-wear additives for ceramic systems.

It is a still further object of the present invention to provide a method of protecting ceramic systems from excessive wear by providing an anti-wear additive.or a fluid composition containing an anti-wear additive, where the anti-wear additive is a monomer compound capable of polymerizing under tribological conditions on the ceramic material in the ceramic system during high wear conditions.

According to the invention, experiments have been conducted which show that fluid compositions contain. ing monomers which are capable of forming polymers significantly reduce the amount of wear experienced by ceramic elements that are subjected to adverse tribological conditions, such as high temperature, pressure, and friction. In the experiments, rubbing ceramic elements were continuously lubricated with a fluid composition containing a very low weight percentage of a monomer compound and a very high weight percentage of a carrier fluid and the effect which the fluid composition had 60 on the wear of the rubbing ceramic elements relative to the effect which the carrier fluid alone had on the wear of the rubbing ceramic elements was compared. Reductions in ceramic wear were, therefore, directly attributable to the presence of the monomer compound in the carrier fluid.

In the experiments, specific ceramic-on-ceramic systems, such as alumina-on-alumina, zirconia-on-zirconia and silicon nitride-on-silicon nitride, were shown to 


\section{3}

experience reductions in wear when lubricated with compositions containing minor amounts of monomer compounds which are capable of polymerization. While the mechanism by which the monomers reduce ceramic wear is not precisely known, there is positive evidence of polymer film formation "in situ" on the surfaces of elements which rub against one another. Tribopolymerization, a term coined by the applicants to describe the "in situ" polymerization of the monomer compounds, may be initiated by high surface temperatures, catalysis, exoelectron emission, and possibly high pressures. The polymer films formed "in situ" are quite thin and do not form in the bulk carrier fluid nor do they form in noncontacting regions of the rubbing surfaces. Rather, the polymer films only form where they are most needed, 15 i.e., the regions experiencing the most severe contact and wear, and they are continuously and simultaneously worn away and reformed under tribological conditions. Therefore, the wear reduction results shown by the experiments would very likely be achieved in other 20 ceramic-on-ceramic systems such as those.including silicon carbide, boron nitride, aluminum nitride, boron carbide, and beryllia, and would also be achieved in ceramic-on-metal and ceramic-on-composite systems, since the key protecting feature conferred by the fluid 25 composition is the "in situ" polymerization of monomers adsorbed on the surface of the ceramic element under tribological conditions.

In the experiments, the monomers were either dissolved, partly dissolved, or dispersed in hexadecane 30 which acted as the carrier fluid. As pointed out above, the carrier fluid itself will act as a lubricant and will help reduce friction relative to a dry ceramic system; however, the experiments performed were designed such that the wear reducing properties observed were 35 directly attributable to the presence of the monomer compound in the carrier fluid. The function of the carrier fluid, of course, is to get the monomer compounds onto the surface of the ceramic element. Therefore, any suitable carrier fluid, such as a mineral oil, a hydrocar- 40 bon fuel, a synthetic oil, or even air where the monomers are applied to the ceramic as a vapor, is deemed to be within the scope of the present invention. Obviously, one would select carrier fluids of proper volatility, boiling point, chemical reactivity, etc., for the specific 45 application. In most of the experiments, the monomers only comprised one percent by weight of the fluid composition. To avoid adversely affecting other properties of the fluid composition and as a matter of cost, the concentration of the monomer compounds in the fluid so composition should probably be limited to a working range of 0.01-10.00\%; however, the inventors do anticipate there will be some situations in which a pure $100 \%$ monomer composition might be preferred for antiwear properties. The experiments discussed below show 55 striking anti-wear effects at low concentrations ranging from 0.1 to $1.0 \%$ by weight.

From the experimental results it can be inferred that the monomer compounds in the fluid composition may, in principle, have any chemical structure and may con- 60 tain carbon, hydrogen, oxygen, nitrogen, phosphorus, sulfur, boron, metals, and other elements. An essential requirement is that the monomer compounds are capable of forming localized surface polymers; they are not polymerized in advance nor in solution. It also appears 6 that the ability of the monomers to be adsorbed on one or both solid contacting surfaces in the ceramic system which is subjected to tribological conditions could be
4

important in the monomer's ability to reduce ceramic wear. Adsorption is a process by which monomer is concentrated at the ceramic surface and it is likely that physisorption and chemisorption could be involved. 5 Two important classes of monomer compounds were investigated and include, first, monomers that can form polymers by condensation type reactions and, second, monomers that can form polymers by addition type reactions.

Examples of monomer compounds in the condensation category involve polymerizable reactants of the $A A$ and $B B$ type or the $A B$ type, in which polymerization is represented according to Equations 1 and 2:

$$
\begin{gathered}
n A A+n B B \rightarrow+A A-B B \frac{1}{\sqrt{n}}+2 n C \\
n A B \rightarrow+A-B \frac{1}{\frac{1}{n}}+2 n C
\end{gathered}
$$

Examples of polycondensation polymers include polyesters, polyamides, polyureas, polyanhydrides, polythioethers, polysulfonamides, polyurethanes, polyphenyl esters, copolymers, and polymers formed by ring-opening polymerization. Particularly suitable candidates of monomers that undergo polycondensation reactions within the scope of this invention are those of the alphaomega category and react according to Equation 3:

$$
n A-R-B \rightarrow+A-R-B+\sqrt{n}+n C
$$

where $A$ is a hydroxy or amino group, $B$ is a carboxylic acid group or its methyl ester, and $R$ is a chain of carbon atoms four to forty in number which can include aromatic, cyclic aliphatic, aliphatic and branched chain 5 groups as well as nitrogen, phosphorus, boron, metals, and other elements. The key feature of the alpha-omega monomers is that the reactive groups, $A$ and-B, are at opposite ends of the molecule. Orientation of the reactive groups at the ends of the molecule avoids steric 40 hindrance problems that may interfere with adsorption and subsequent tribopolymerization on the ceramic surface, etc: It is also anticipated that mixtures of monomers which can form polymers by a polycondensation reaction are within the scope of this invention and a typical reaction scheme is presented below as Equation 4:

$A-R_{1}-A+B-R_{2}-B \rightarrow+\frac{+}{B \mathrm{~J}_{n}}+{ }_{n} C-R_{1}-A-B-R_{2}-\quad$ Eq.4

where $R_{1}$ and $R_{2}$ may be aliphatic chains of different lengths, i.e., one short and one long.

Monomer compounds in the addition category include an unsaturated ethylenic unit such as that shown below in Equation 5:<smiles>[R4]C([R4])=C([R4])[R]</smiles>

Eq. 5

where the $\mathbf{R}$ groups are either hydrogen or some other group. Particularly effective monomers for reducing ceramic wear are those in which $R_{1}=R_{2}=R_{3}=H$ with $R_{4}$ being an aliphatic, aromatic, cyclic, or some other group. Having only one non-hydrogen group may avoid steric hindrance problems and favor surface poly- 


\section{5}

merization. The addition polymerization of a typical monomer is represented by Equation 6:

$$
n \mathrm{CH}_{2}=\mathrm{CHR} \rightarrow+\mathrm{CH}_{2}-\mathrm{CHR} \frac{\mathrm{T}}{\sqrt{n}}
$$

Examples of addition polymers include polystyrene, polyvinyl chloride, polyacrylonitrile, polyvinyl acetate, polyvinyl alcohol, polymethyl methacrylate, polyethylene, polytetrafluoroethylene, various copolymers, and analogs of these polymers formed from higher molecular weight polymers.

The ability to reduce ceramic wear should allow less expensive ceramics to be substituted for more expensive ceramics in some ceramic systems. For example, the reduced wear experienced by alumina components when a fluid composition containing monomer compounds capable of polymerization is used as a lubricant may allow the use of alumina in systems which typically have required silicon nitride (a ceramic which is known for its inherent anti-wear properties). Since alumina is 20 far less expensive to produce than silicon nitride, the wear reducing capability of the proposed fluid compositions is believed to be extremely significant.

\section{BRIEF DESCRIPTION OF THE DRAWINGS}

The foregoing and other objects, aspects and advantages will be better understood from the following detailed description of a preferred embodiment of the invention with reference to the drawings, in which:

FIG. 1 is a diagram showing an apparatus used to 30 conduct pin-on-disk experiments;

FIGS. $2 a$ and $2 b$ are before and after cross-sectional side views, respectively, of a ceramic pin used in the pin-on-disk apparatus of FIG. 1;

FIG. 3 is a front view of the pin shown in FIG. $2 b 35$ illustrating the worn portion of the pin;

FIGS. $4 a$ and $4 b$ are before and after cross-sectional side views, respectively, of a ceramic disk used in the pin-on-disk apparatus of FIG. 1;

FIGS. $5 a$ and $5 b$ are before and after top views, re- 40 spectively, of the ceramic disk shown in FIGS. $4 a$ and 4b;

FIGS. $6 a$ through $6 h$ are tables showing the experimental results for various groups of monomer compositions in alumina-on-alumina pin-on-disk experiments;

FIG. 7 is a table showing the experimental results for different concentrations of methyl-2-acrylamido-2methoxyacetate in alumina-on-alumina pin-on-disk experiments;

FIG. $8 a$ is a table showing the experimental results 50 for alumina-on-alumina pin-on-disk experiments wherein a one percent by weight solution of the monoester of $\mathrm{C}_{36}$ dimer acid and ethylene glycol dissolved in hexadecane is used as the lubricant and different loads are applied;

FIG. $8 b$ is a reaction scheme for the synthesis of the monoester of $\mathrm{C}_{36}$ dimer acid and ethylene glycol;

FIG. 9 is a table showing the experimental results for zirconia-on-zirconia pin-on-disk experiments wherein one percent by weight mixtures of various monomers 60 dissolved in hexadecane were used as the lubricant;

FIG. 10 is a table showing the experimental results for silicon nitride-on-silicon nitride pin-on-disk experiments wherein one percent by weight mixtures of various monomers dissolved in hexadecane were used as the lubricant; and

FIG. 11 is a table showing the experimental results for fretting wear tests where hexadecane and hexa-
6

decane and one percent by weight of the $C_{36}$ dimer acid and ethylene glycol monoester are used as the lubricants in a zirconia ball and graphite-epoxy disk system.

5 DETAILED DESCRIPTION OF A PREFERRED EMBODIMENT OF THE INVENTION

Referring now to the drawings, and more particularly to FIG. 1, there is shown a diagram of a pin-ondisk test apparatus represented generally as 10 . The test apparatus 10 includes a table 12 capable of high speed rotation about an axis indicated by arrow 14 . The speed of rotation of the table 12 can be accurately regulated by a motor controller. On the table 12 is positioned a vibration isolating platform 16 for holding a ceramic disk 18. The vibration isolating platform 16 may be a rubber material and serves to isolate adverse vibration affects from being transferred from the table 12 to the ceramic disk 18. The ceramic disk 18 is held on the vibration isolating platform 16 by a cylindrical disk holder 20. A rubber washer 22 is placed between the cylindrical disk holder 20 and the ceramic disk 18 so that a lubricant 24 can be held in the volume created by the top portion of the cylindrical disk holder 20 which extends above the ceramic disk 18.

A ceramic ball 26 positioned on the end of a pin 28 contacts the ceramic disk 18 during the experiments. The ceramic ball 26 is firmly secured to the pin 28 during testing by using an epoxy resin; hence, it does not rotate during the test run, rather it slides against the disk 18. Weights 30 hung on the end of a loading arm 32 exert a downward force 34 on the pin 28 which holds the ball 26 in contact with the ceramic disk 18 during a test run. The amount of downward force 34 is controlled by the amount of weight $\mathbf{3 0}$ on the loading arm 32 , and for these experiments, the downward force 34 was controlled to be five or ten or twenty Newtons (N) depending on the experiment. For example, a force 34 of $20 \mathrm{~N}$ gives a calculated mean Hertzian pressure of $2.59 * 10^{9} \mathrm{~N} / \mathrm{m}^{2}$ for alumina-on-alumina for this load and geometry. These are very extreme test conditions which produce contact stresses which equal or exceed those existing critical tribological applications, e.g., gears, cams, and valve lifters in automotive engines, etc.

45 How well the lubricant 24 protects the ceramic disk 18 and the ceramic ball 26 from wear is the primary focus of this invention.

In the experiments reported below in FIGS. $6 a-6 h, 7$, and 8 , new ceramic disks 18 and balls 26 made of alumina were used for each test run. Both alumina disks 18 and balls 26 were of $99.5 \%$ purity. Alumina has an elastic modulus of $3.7 * 10^{11} \mathrm{~N} / \mathrm{m}^{2}$, a hardness of $1.47 * 10^{10} \mathrm{~N} / \mathrm{m}^{2}$, a Poissons ratio of 0.22 a density of $3890 \mathrm{~kg} / \mathrm{m}^{3}$, and a thermal conductivity of 35.6 $55 \mathrm{~J} /(\mathrm{sec})(\mathrm{m})(\mathrm{k})$. The ceramic disks 18 were $25 \mathrm{~mm}$ in diameter. An average of ten measurements indicated that the alumina disks 18 had a surface roughness of 0.73 micrometers. The ceramic balls 26 were grade 5 alumina and were $3.175 \mathrm{~mm}$ or one eighth of an inch in 0 diameter. The ceramic disks 18 and balls 26 were ultrasonically cleaned in methanol and then in hexane before each test.

Several lubricant compositions 24 were prepared to determine their ability to reduce the amount of wear on 65 the alumina disk 18 and alumina ball. The lubricant compositions 24 consisted of a hexadecane carrier fluid together with one of the additives shown in FIGS. $6 a-6 h, 7$, or 8 . The additives were selected as monomers 


\section{7}

capable of forming polymer compounds. The monomers did not polymerize in solution and were either dissolved in, partially dissolved, or dispersed in the hexadecane carrier fluid. The lubricant compositions 24 were all prepared as one percent by weight solutions in hexadecane, except as otherwise specified. Hexadecane is a pure, well-defined carrier fluid of known chemical structure and was selected for its relatively inert characteristics for test purposes. The function of the carrier fluid, of course, is to get the monomer compounds onto the surface of the ceramic element. Therefore, any suitable carrier fluid, such as a mineral oil, a hydrocarbon fuel, a synthetic oil, or even air where the monomers are applied to the ceramic as a vapor, is deemed to be within the scope of the present invention. Obviously, one would select carrier fluids of proper volatility, boiling point, chemical reactivity, etc., for the specific application. Most of the compositions 24 prepared were clear and colorless except the composition with the 4-vinylbiphenyl additive was brown, the composition 20 with the 2-vinylnaphthalene additive was red, the composition with the 9-vinylanthracene additive was yellow, and the composition with the vinyl ferrocene was amber. Most of the additive compounds were soluble in hexadecane; however, 2-vinylnaphthalene, acrylamide, 25 methacrylamide, and methyl-2-acrylamido-2-methoxyacetate were only partially soluble.

In each experiment, $0.7 \mathrm{ml}$ of the lubricant composition 24 was placed in the volume created by the cylindrical disk holder 20 before the ball 26 was brought into 30 contact with the disk 18 . The ball 26 contacts the disk 18 at a point $8 \mathrm{~mm}$ from the center of the disk 18 and creates a channel in the disk 18 as it wears. When the table 12 has a rotational speed of 300 revolutions per minute (rpm), the ceramic disk 18 has velocity of 0.25135 $\mathrm{m} / \mathrm{s}$. During each test run, the machine was started with a constant speed of $300 \mathrm{rpm}$ and run for thirty three minutes which gave a sliding distance of the ball 26 relative to the disk 18 of 500 meters.

FIGS. $2 a$ and $2 b$ show the ball 26 before and after a 40 thirty three minute test run, respectively. Note that the ball 26 has been worn down to a level 36 via the sliding contact with the disk 18. FIG. 3 shows that the level 36 is a circular area on the face of the spherical ball 26. By determining the area, the volume of the spherical ball 26 which has been worn away during the test run can be calculated using well known techniques. FIGS. $4 a$ and $5 a$ show a ceramic disk 18 before a thirty three minute test run and FIGS. $4 b$ and $5 b$ show the ceramic disk 18 after the test run. Channel $\mathbf{3 8}$ is worn into the ceramic disk 18 at the point the ball 25 contacts the disk 18 while it is rotated. By determining the area of a cross-section of the channel 38 and determining the radius of the channel 38, the volume of the channel 38 can be calculated by well known techniques. A photomacroscope and stylus profilometer were used to make the necessary measurements on the ceramic disk 18 and ceramic ball 26.

FIGS. 6a-6h show the pin-on-disk test results for an alumina-on-alumina system wherein the lubricant compositions tested contained one percent by weight ( 1 wt $\%)$ of several addition type monomers dissolved in a hexadecane carrier fluid. In the experiments, the alumina-on-alumina system was subjected to 20 newtons (N) of force. The wear on the disk 18 and the wear on the ball 26 were determined by photomacroscopic and profilometric techniques and reported in volume units. The two volumes were added together to determine a
8

total volume worn away. The total volume worn away from the ceramic disk and ceramic ball when a test lubricant composition containing one percent by weight of a monomer was used was then compared to the total volume worn away from a ceramic disk and a ceramic ball when hexadecane, without a monomer additive, was used as the lubricant. When pure hexadecane without a monomer additive was used as the lubricant the average worn volume of the alumina disk was $10360^{*} 10^{-3} \mathrm{~mm}^{3}$ and the average worn volume of the alumina ball was $109 * 10^{-3} \mathrm{~mm}^{3}$, so the average total worn volume for the alumina-on-alumina system for hexadecane without a monomer additive was $469 * 10^{-3}$ $\mathrm{mm}^{3}$. Therefore, the percentage reductions in wear for 15 the alumina disks and balls reported in FIGS. $6 a-h$ is a direct result of having the monomer in solution with the hexadecane carrier fivid. It is noted that a $50 \%$ reduction in wear means that the life of the ceramic part will be doubled, a $67 \%$ reduction in wear means tripling the life, and an $80 \%$ reduction in wear is equivalent to increasing the wear life of a ceramic element by a factor of five (e.g., 500\% increase in life expectancy). Hence, the results reported below have significant life increasing implications for ceramic systems.

FIG. $6 a$ shows that a fluid composition containing addition type monomers of the general structure $\mathrm{CH}_{2}=\mathrm{CHX}$ and having an ethylene end unit and an aliphatic side chain can reduce ceramic wear. Specifically, a fluid composition containing 1 wt \% of 1 -dodecene or 1-hexadecene or 1-octadecene dissolved in a hexadecane carrier fluid can result in a significant reduction in wear for rubbing alumina components over that which can be achieved with the hexadecane carrier fluid alone. FIGS. $6 b$ and $6 c$ show that all of the fluid compositions containing 1 wt $\%$ solutions of vinyl aromatic monomers and vinyl acrylate monomers in a hexadecane carrier fluid which were tested in these experiments were very effective for reducing wear. FIG. $6 b$ specifically shows that solutions containing 1 wt $\%$ of 40 either styrene, 4-vinylbiphenyl, or 2-vinylnaphthalene could be expected to double the life of alumina parts in a ceramic system and FIG. $6 c$ specifically shows that solutions containing 1 wt \% of either n-butyl methacryate, lauryl methacrylate, or iso-decyl acrylate could be 45 expected to triple the life of alumina parts in a ceramic system.

FIG. $6 d$ shows that the compositions containing 1 wt $\%$ vinyl acetate or 1 wt \% vinyloctadecyl ether dissolved in hexadecane were extremely effective in reducso ing ceramic wear. Specifically, the 1 wt $\%$ vinyl acetate solution reduced wear by $70 \%$ and the 1 wt \% vinyloctadecyl ether solution reduced wear by $74 \%$. As pointed out above, reducing ceramic wear by greater than $67 \%$ indicates that the life of the ceramic part will be increased by greater than $300 \%$. FIGS. $6 d$ and $6 h$ show that solutions containing 1 wt $\%$ acrylamide or methacrylamide in hexadecane were ineffective at reducing ceramic wear over that which was achieved with hexadecane alone. FIG. 6e shows that both solu60 tions containing 1 wt \% vinyl cyclooctane or 1 wt \% vinyl ferrocene dissolved in hexadecane were very effective in reducing wear in the alumina-on-alumina pin-on-disk experiments.

FIG. $6 f$ shows the results for alumina-on-alumina 65 pin-on-disk experiments for solutions containing monomers capable of addition type polymerization wherein the monomers have a $\mathrm{CH}_{2}=\mathrm{CH}-\mathrm{X}-\mathrm{CH}=\mathrm{CH}_{2}$ structure and are different from those reported in FIGS. 6a-e 
in that the monomers discussed in FIG. $6 f$ have vinyl groups at each end of the molecule and the monomers discussed in FIGS. 6a-e only have one vinyl group at one end of the molecule. In particular, FIG. $6 f$ shows that hexadecane solutions containing 1 wt $\%$ diallyl phthalate or 1 wt \% diallyl succinate were very effective at reducing ceramic wear.

FIGS. $6 g$ and $6 h$ show the test results for pin-on-disk experiments in an alumina-on-alumina system where the lubricant compositions included monomer additives capable of polymerizing by an addition type mechanism dissolved in hexadecane where the monomers each had more than one constituent connected to the vinyl group. FIG. $6 \mathrm{~g}$ shows that the fluid composition containing 1 wt \% trans $\beta$-methylstyrene dissolved in hexa- 15 decane actually significantly increased wear on the rubbing alumina elements over the wear which occurs when hexadecane alone is used as the lubricant. However, when compositions containing a 1 wt \% monomer additive which had constituents connected to the vinyl 20 group in the cis configuration, i.e., cis-11-hexadecene-1ol and cis-11-hexadecen-1yl-acetate, were tested in the pin-on-disk experiments, significant wear reduction was achieved, e.g., $43 \%$ and $45 \%$ wear reduction over an alumina-on-alumina system in which hexadecane alone 25 is utilized, respectively. The difference in the ability of the monomers to reduce wear may be the result of cis bonded molecules interfacing with the ceramic better than trans bonded molecules. FIG. $6 h$ shows that effective wear reduction can be achieved with some compo- 30 sitions that contain monomers having two constituents connected to the same carbon of the vinyl group, i.e., effective alumina wear reduction was achieved using the fluid compositions containing either $1 \mathrm{wt} \% 1,1$ diphenylethylene or 1 wt \% $\alpha$-methyl styrene dissolved 35 in hexadecane.

FIG. 7 shows alumina-on-alumina pin-on-disk test results for a composition containing 1 wt \%o methyl-2acrylamido-2-methoxyacetate dissolved in hexadecane. In the experiments, the alumina-on-alumina system was 40 subjected to $20 \mathrm{~N}$ of force. Three different compositions were prepared, i.e., $0.02 \%, 0.10 \%$ and $1.00 \%$ by weight solutions of methyl-2-acrylamido-2-methoxyacetate in hexadecane, respectively, and tested for their wear reducing properties. As can be seen from FIG. 7, meth- 45 yl-2-acrylamido-2-methoxyacetate is particularly effective at reducing wear in an alumina-on-alumina system, e.g., even at concentrations as low as 0.02 wt \% wear was reduced by more than $80 \%$.

FIG. $8 a$ shows experimental pin-on-disk results in an 50 alumina-on-alumina system where the lubricant comprised 1 wt $\%$ of the $\mathrm{C}_{36}$ dimer acid and ethylene glycol monoester dissolved in hexadecane and where the force on the rubbing surfaces varied from 5 to 20 newtons (N). The $\mathrm{C}_{36}$ dimer acid and ethylene glycol monoester 55 has the general structure of HOOC $-\mathrm{R}-\mathrm{OH}$ where $\mathrm{R}$ contains thirty eight carbon atoms. The $\mathrm{C}_{36}$ dimer acid and its reaction with ethylene glycol to form the monoester is discussed in U.S. Pat. No. 3,180,832 to Furey et al. and in U.S. Pat. No. 3,429,817 to Furey et al. and 60 those patents are herein incorporated by reference. The synthesis of the $\mathrm{C}_{36}$ monoester is generally diagrammed in FIG. $8 b$ wherein the reaction is monitored by the amount of water produced and by the observation of FIIR absorption intensities of ester and acid carbonyl 65 bands. FIG. $8 a$ shows that the monoester is more effective in reducing wear at the highest load. Possibly higher surface temperatures are produced in the contact zone at the higher loads and these higher temperatures aid in "in situ" polymerization.

A pin-on-disk experiment using a 1 wt \% solution of the $\mathrm{C}_{36}$ dimer acid and ethylene glycol monoester dis5 solved in hexadecane as a lubricant for a sapphire-onsapphire system (single crystal, polished balls and optical flat disks) was conducted at a load of $10 \mathrm{~N}$ at a 300 rpm rotation speed for $1 \mathrm{hr}$. In the experiments, the coefficient of friction for various systems, with and

10 without lubricants, were determined. Table 1 shows the effect of fluids on friction in the sapphire-on-sapphire system:

TABLE 1

\begin{tabular}{lcc}
\hline & \multicolumn{2}{c}{ COEFFICTENT OF FRICTION } \\
\cline { 2 - 3 } Fluid & Average & Maximum \\
\hline None (dry) & 0.34 & 0.58 \\
distilled $\mathrm{H}_{2} \mathrm{O}$ & 0.20 & 0.49 \\
Hexadecane & 0.17 & 0.22 \\
Hexadecane + & 0.09 & 0.14 \\
$1 \% \mathrm{C}_{36}$ dimer acid/ & & \\
ethylene giycol & & \\
mozester & & \\
\hline
\end{tabular}

Table 1 shows that the presence of hexadecane between 25 the sapphire elements significantly decreases friction over dry systems and that the hexadecane and 1 wt \% $\mathrm{C}_{36}$ monoester solution had an even lower coefficient of friction. As discussed above in conjunction with FIG. $8 a$, the presence of the $C_{36}$ dimer acid/ethylene glycol monoester in the hexadecane will result in reducing sapphire wear over that which can be achieved with hexadecane alone. An interesting result from this study was that when distilled water was used as the lubricant, nearly twenty times as much wear was experienced by the sapphire ball relative to the dry system, e.g., $380^{*} 10^{-3} \mathrm{~mm}^{3}$ in dry case and $7600^{*} 10^{-3} \mathrm{~mm}^{3}$ when water was used.

An additional experiment using a 1 wt \% solution of the $\mathrm{C}_{36}$ dimer acid and ethylene glycol monoester dissolved in hexadecane as a lubricant for a sapphire-onsapphire system was conducted at double the load or $20 \mathrm{~N}$ in the pin-on-disk environment for one hour. Table 2 shows the average ball volume worn away:

TABLE 2

\begin{tabular}{lc}
\hline \multicolumn{2}{c}{ Pin-On-Disk Tests at 20 N Losd for 1 Hour } \\
Additive in & $\begin{array}{c}\text { Average Ball wer } \\
\text { Volume in } 10^{-3} \mathrm{~mm}^{3}\end{array}$ \\
\hline Hexadeane & 840 \\
None & 200 \\
$1 \%$ C 36 dimer acid/ethylene & \\
glyeol monoester & \\
\hline
\end{tabular}

The solution containing $\mathrm{C}_{36}$ dimer acid/ethylene glycol monoester dissolved in hexadecane allowed signifi55 cantly less wear to occur on the sapphire ball. The results in Table 2 demonstrate that tribopolymerization is a very effective approach to lubricating ceramics.

In addition to the alumina-on-alumina systems, where wear reduction results were reported in conjunction 60 with FIGS. $6 a-h, 7 a-b$, and $8 a-b$, and the sapphire-onsapphire systems where wear reduction results are reported in Table 2, pin-on-disk experiments have been conducted in a zirconia-on-zirconia $\left(\mathrm{ZrO}_{2}-\mathrm{on}-\mathrm{Z}_{\mathrm{rO}}\right)$ system and in a silicon nitride-on-silicon nitride $\left(\mathrm{Si}_{3} \mathrm{~N}_{4}\right.$ 65 on-Si3 $\mathrm{N}_{4}$ ) system. In the $\mathrm{ZrO}_{2}-\mathrm{on}_{-}-\mathrm{ZrO}_{2}$ experiments, the zirconia balls made of pure $\mathrm{Z}_{2} \mathrm{O}_{2}$ stabilized form $\mathrm{SZY}-\mathrm{H}$ and were grade 10 . In the $\mathrm{Si}_{3} \mathrm{~N}_{4}-\mathrm{On}-\mathrm{Si}_{3} \mathrm{~N}_{4}$ experiments, the balls were the SAN-2 type, grade 25 . 


\section{1}

The conditions for the pin-on-disk experiments in both the $\mathrm{ZrO}_{2}$-on- $\mathrm{ZrO}_{2}$ and $\mathrm{Si}_{3} \mathrm{~N}_{4}-\mathrm{on}-\mathrm{Si}_{3} \mathrm{~N}_{4}$ systems were a $20 \mathrm{Newton}$ load and rotation of the disk at $300 \mathrm{rpm}(0.25$ meters/second $(\mathrm{m} / \mathrm{s})$ for 33 minutes for a total sliding distance of 500 meters. In these experiments, only the average ball wear was measured since the disk wear was low and difficult to measure accurately. The volume of the ball worn away when hexadecane alone was used as the lubricant in the $\mathrm{ZrO}_{2}-\mathrm{On}-\mathrm{ZrO}_{2}$ system was $1.73^{*} 10^{-3} \mathrm{~mm}^{3}$. The volume of the ball worn away when hexadecane alone was used as the lubricant in the

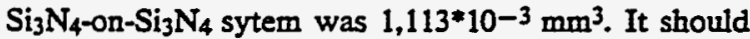
be noted that $\mathrm{Si}_{3} \mathrm{~N}_{4}$ has become an important engineering material because of its inherent low wear properties and that in these pin-on-disk experiments the $\mathrm{Si}_{3} \mathrm{~N}_{4}$ ball had much less wear than alumina and less wear than zirconia when hexadecane alone was used as the lubricant.

FIG. 9 reports the percentage reduction in wear for the zirconia ball when fluid compositions containing 120 wt \% of a monomer dissolved in hexadecane were used as the lubricants. Like the experiments described above, the percentage reduction in wear is the result of the comparison of the volume worn away when hexadecane alone is used as the lubricant in the zirconia-on- 25 zirconia system to the volume worn away when the composition containing the monomer dissolved in hexadecane is used as the lubricant. FIG. 9 shows that all lubricant solutions tested were able to reduce wear in the zirconia-on-zirconia system. In particular, solutions 30 containing either 1 wt $\%$ vinyl octadecyl ether or 1 wt $\%$ lauryl methacrylate dissolved in hexadecane were able to reduce wear by as much as $45 \%$. 11-amino undecanoic acid was only partly soluble in hexadecane, yet the 1 wt \% solution of 11 -amino undecanoic acid 3 was able to reduce wear of the ceramic ball by $29 \%$ over that where hexadecane alone was used as the lubricant. The $\mathrm{C}_{36}$ dimer acid/ethylene glycol monester and the 11-amino undecanoic acid are examples of monomers capable of condensation type polymerization and the 1-dodecene, 1-eicosene, lauryl methacrylate, diallyl phthalate, and vinyl octadecyl ether are examples of monomers capable of addition type polymerization.

FIG. 10 reports the percentage reduction in wear for the silicon nitride ball when fluid compositions contain- 45 ing 1 wt \% of a monomer dissolved in hexadecane were used as the lubricant. Like the experiments described above, the percentage reduction in wear is the result of the comparison of the yolume worn away when hexadecane alone is used as the lubricant in the $\mathrm{Si}_{3} \mathrm{~N}_{4-0 \mathrm{n}}$ - 50 $\mathrm{Si}_{3} \mathrm{~N}_{4}$ system to the volume worn away when the composition containing the monomer dissolved in hexadecane is used as the lubricant. FIG. 10 shows that solutions containing either 1 wt $\%$ diallyl phthalate or 1 wt \% 11-amino undecanoic acid dissolved in hexadecane were able to reduce wear by approximately half; therefore, use of these lubricant solutions could double the life of ceramic machines which utilize silicon nitride. In addition, FIG. 10 shows that solutions containing either 1 wt \% $\mathrm{C}_{36}$ dimer acid/ethylene glycol monoester or 1 wt \% methyl-2-acrylamido-2-methoxy acetate dissolved in hexadecane were able to reduce wear by an impressive $72 \%$ or $65 \%$, respectively; therefore, use of these lubricant solutions could effectively triple the life of ceramic machines which utilize silicon nitride. These are the only experiments known by the inventor which demonstrate lubricant solutions which can significantly reduce the wear of silicon nitride which itself is a low-

\section{2}

wear ceramic material. Because silicon nitride is an expensive material and is used in very hostile environments because of its low-wear properties, lubricant solutions which can increase the life of silicon nitride 5 should be extremely useful.

In a totally different high-contact stress system designed to study fretting wear and fretting corrosion, additional experiments were carried out using zirconia balls on graphite-epoxy flat disks. Fretting is a form of 10 wear which occurs when two bodies in contact undergo vibratory/oscillatory motion. Fretting is important in joints, fastenings, bearing supports, and a wide variety of "stationary" contact situations. In the experiments, fretting tests were conducted at three different normal 5 loads, i.e., $40 \mathrm{~N}, 90 \mathrm{~N}$, and $130 \mathrm{~N}$ in the zirconia/graphite-epoxy system. The frequency of oscillation was 50 $\mathrm{Hz}$ and the amplitude was set at 200 microns (peak to peak). The tests were conducted for one hour or 180,000 cycles. The composite specimens were made by laying up prepreg layers of graphite-epoxy in an alternating orientation, e.g., zero and ninety degrees. The zirconia balls were five eighths of an inch in diameter and were grade 10 . The zirconia balls were loaded and oscillated against the composite in the anti-parallel direction. Friction was measured and recorded by means of a strain gauge ring and wear on the composite was determined by photomacrography.

FIG. 11 shows the fretting test results at different applied loads in the zirconia/graphite-epoxy system where hexadecane alone and a composition of hexadecane and 1 wt $\% C_{36}$ dimer acid/ethylene glycol monoester were used as the lubricants. The addition of the $1 \%$ of monoester resulted in a reduction in disk wear of as much as $48 \%$. Furthermore, at the higher load $(130 \mathrm{~N})$, the monoester was more effective at wear reduction. Greater wear reduction with increasing load may be the result of increased surface temperatures favoring tribopolymerization as discussed above in conjunction with FIG. 8a. Effects on friction varied from a slight (5-7\%) increase to a $30 \%$ decrease depending on the load.

Mixed system fretting experiments were conducted using the fretting machine where the mixed systems included 52100 alloy steel balls (o inch in diameter) in oscillating contact against alumina and graphite-epoxy composites. These tests were conducted for one hour at an applied load of $86 \mathrm{~N}$, frequency of $60 \mathrm{~Hz}$, and an amplitude of 225 microns (peak to peak). In the experiments, hexadecane alone and a composition of hexadecane and 1 wt $\% C_{36}$ dimer acid/ethylene glycol monoester were used as the lubricants. In the steel-onalumina system, it was found that the addition of the $\mathrm{C}_{36}$ dimer acid/ethylene glycol monoester actually in55 creased friction somewhat, but completely eliminated wear on the steel ball. In the steel-on-graphite system, the bexadecane lubricant was able to lower friction and wear over the unlubricated (dry) case; however, wear on the graphite-epoxy disk was still substantial. When 60 the fluid composition comprised of 1 wt \% $C_{36}$ dimer acid/ethylene glycol monoester dissolved in hexadecane was used as the lubricant, no wear on the disk could be detected even ander a microscope.

While the invention has been described in terms of its 65 preferred embodiment where compositions containing specific monomer compounds can be used to reduce the wear of rubbing ceramic components, those skilled in the art will recognize that the invention can be prac- 
13

$5,407,601$

ticed with modification within the spirit and scope of the appended claims.

Having thus described our invention, what we claim as new and desire to secure by Letters Patent is the following:

1. A method of reducing ceramic wear, comprising the steps of:

providing a ceramic material having a surface which will be exposed to rubbing contact with another material; and

appying a ceramic lubricating composition to said surface which will be exposed to rubbing contact with another material, said ceramic lubricating composition comprising $90.0 \%-99.9 \%$ by weight of a carrier fluid selected from the group consisting 15 of mineral oils, hydrocarbon fuels, synthetic oils and hexadecane, and $0.01-10 \%$ by weight of methyl-2-acrylamido-2-methoxyacetate dissolved or dispersed in said carrier fluid, said ceramic lubricating composition reducing wear of said ceramic 20 material at said surface exposed to rubbing contact.

2. A method as recited in claim 1 wherein said ceramic material is selected from the group consisting of alumina, zirconia, and silicon nitride.

3. A method as recited in claim 1 wherein said meth- 25 yl-2-acrylamido-2-methoxyacetate is present in said composition at a level ranging from $0.1-1.0 \%$ by weight.

4. A method of reducing ceramic wear, comprising the steps of:

providing a ceramic material having a surface which will be exposed to rubbing contact with another material; and

applying a ceramic lubricating composition to said surface which will be exposed to rubbing contact 35 with another material, said ceramic lubricating composition comprising $90.0 \%-99.9 \%$ by weight of a carrier fluid selected from the group consisting of minneral oils, hydrocarbon fuels, synthetic oils, and hexadecane, and $0.01-10 \%$ by weight of an 40 acrylate monomer selected from the group consisting of n-butyl methacrylate, lauryl methacrylate, and isodecyl acrylate, said acrylate monomer dissolved or dispersed in said carrier fluid, said ce- 


\section{Virginia Tech Research on Novel Method of Lubrication Is Leading to Diverse Commercial Applications}

An advanced technology for the lubrication of metals and ceramics, developed by Virginia Tech Mechanical Engineering Professor Michael Furey and Professor Czeslaw Kajdas of the Warsaw University of Technology, Institute of Chemistry in Poland, has been patented and is in the process of being licensed for commercial applications.

The technology is based on the concept of tribopolymerization first proposed by Furey several years ago and later refined during several years of collaborative research with Kajdas at Virginia Tech. Tribology (from the Greek "tribo", to rub) is the study of friction, wear, and lubrication. Tribopolymerization is defined as the planned and continuous formation of protective polymeric films directly on rubbing surfaces by the use of selected monomers capable of forming polymer films "in situ."

Due to the high surface temperatures in regions of contact, and possibly to emission of charged particles, thin polymeric films form in localized areas of greatest wear. These invisible films are continuously formed and replenished only in critical regions of contact and not on other surfaces.

The concept developed by Furey and Kajdas is one of molecular design; it is not centered on the use of one or only a few compounds, but on classes of specific chemical structures. The process works with a variety of surfaces, including metals and ceramics.

Why the interest in friction, wear, and lubrication of ceramics? First of all, ceramics can be used at much higher temperatures than alloy steels commonly used in engines and machines. Ceramics also are harder and more resistant to abrasive or erosive wear and they do not corrode. In addition, some ceramics are much lighter in weight than conventional steel base materials.

Examples of the potential uses of ceramics include ceramic engines for higher temperature operation and greater thermodynamic efficiency, advanced propulsion systems, turbomachinery, gas turbines, aerospace bearings, automotive engine components, cutting and machining of difficult alloys, biomedical (e.g., artificial joints), ceramic heads for magnetic recording, and any tribological system operating under high temperature, abrasive, or corrosive conditions.

Nathan Katz of the U.S. Army Materials Laboratory estimates that if such low heat-loss engines were used in diesel engines, the annual fuel savings 
would exceed $\$ 5$ billion in the U.S. alone. Katz estimates that fuel savings in diesel and gas turbine engines could range from 15 to 40 percent.

A barrier to many commercial uses of ceramics is the fact that conventional lubrication methods, which were developed for steel systems, are often ineffective for ceramic systems.

Earlier research conducted by Furey and Kajdas and funded by the National Science Foundation (NSF) and Virginia's Center for Innovative Technology (CIT) found that compounds selected, developed, or synthesized on the basis of the concept of tribopolymerization are strikingly effective for reducing wear and friction for ceramics (including alumina, zirconia, and silicon nitride) as well as steel when used in concentrations as low as $0.02-1.0$ percent in either a hydrocarbon carrier fluid or gas.

In the liquid phase, the technology developed by Furey and Kajdas brought about wear reductions of $40-80$ percent. In the vapor phase (i.e., in nitrogen), wear reductions with ceramics of up to 99 percent and friction reductions of $40-50^{\circ}$ percent were observed. Surprisingly, the additives are more effective at higher temperatures.

In 1995, Furey and Kajdas obtained a patent on tribopolymerization as a method of ceramic lubrication. The researchers recently filed three patent applications for use of the concept with both ceramics and metals.

Also in 1995, the U.S. Government's Energy-Related Inventions Program, a joint program of the Department of Energy and the National Institute of Standards and Technology, selected this invention as one of 12 from over 600 applications as an enabling technology for the development of future high temperature engines. Furey and Kajdas received a $\$ 100,000$ grant from the program to demonstrate the viability of their concept under higher temperatures and loads.

Triad Investors Corp. recently signed agreements with Virginia Tech and the CIT to fund additional research to promote the further development, licensing, and marketing of tribopolymerization as an effective and innovative approach to lubrication. Triad is funding $\$ 100,000$ in research in three areas: Novel fuel lubricity additives for two-stoke engines, tribopolymerization as a novel method of lubricating ceramic machining/cutting tools, and vapor phase lubrication of metals and ceramics at high temperatures by tribopolymerization.

With the support of Triad, other applications of this technology are also 
being explored, including the area of diesel fuel lubricity-a problem of increasing concern since cleaner low-sulfur fuels have inherently poor lubrication characteristics, leading to excessive fuel pump and injector wear. Stefan Strein, an investment associate for Triad, says, "The Furey/Kajdas technology has great potential for development into viable commercial applications."

All of this is the result of a continuous collaborative effort between Furey and Kajdas that began when the two met at an international conference, after which Kajdas came to Virginia Tech as a visiting professor in 1986. He has returned to carry out joint research with Furey for each of the last 10 summers, as a co-investigator on research grants from the NSF. Furey and Kajdas have presented papers on this work at international tribology conferences in the U.S., Poland, Hungary, Finland, Japan; Australia, and Germany.

Several students have worked with Furey and Kajdas on tribopolymerization research at Virginia Tech, including eight graduate students, a Fulbright scholar from Poland, and five undergraduates, three of whom received summer research fellowships in a program for women and minority engineering students.

Furey and Kajdas believe that their tribopolymerization technology will find use in a wide variety of applications, particularly where ashless, biodegradable, effective antiwear/antifriction compounds are needed. "Dr. Kajdas and I see 1996 as the year in which the results of our many years of fundamental research in tribopolymerization will pay off in industrial applications and new advances for ceramics, metals, and other materials," says Furey with conviction.

College of Engineering

Virginia Tech

Blacksburg, VA 24061

March 1996 


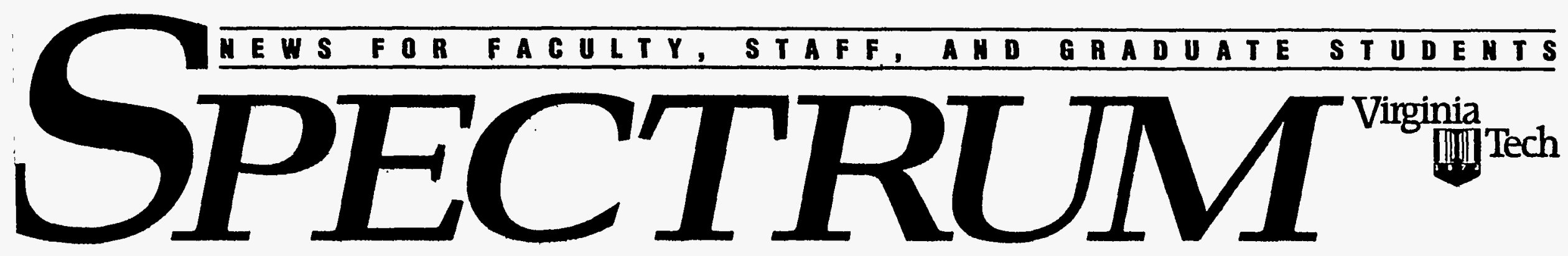

\section{Tech twelfth nationally in patents}

By Susan Trulove

Virginia Tech faculty and staff members and students eamed 29 patents during 1995-making the university twelfth in the nation for number of patents eamed among the 158 colleges and universities receiving at least one patent.

Virginia Tech is first in the state and fifth in the country among universities without medical schools (hchind MIT, CalTcch, lowa State, and NC State), acconding to a study by the Association of University Technology Managers, Inc.

Discoverics include compositions for reducing wear on ceramic surfaces, improved anti-cancer drugs. and a melhod for dewatering fine coal withoul thermalenergy use.

Michael Furey, professor of mechanical cngineering, and Czeslaw Kajdas of the Warsaw University of Technology, Institute of Chemistry, Poland, have developed a new lubrication technology. Special molecules are introduced to the surface of ceramics or steel resulting in the formation of polymer films that reduce friction and wear. The beneficial effects of the additives are more pronounced at higher temperatures. Ccramic and steel components in effect become self-lubricating. which could make high- temperature, light-weight engines possible. The U. S. Energy-Related Inventions Program has estimated that if such low heat-loss engines were used in diesel trucks, the annual fucl saving would exceed $\$ 5$ billion in the U.S. alone.

Chemistry professor David Kingston's research with the anti-cancer compound taxol is aimed at increasing, enhancing. and understanding this natural compound, which comes from the bark of the scarce Pacific Ycw. Kingston and his associate Jingyu Liang received a patent for water-soluble analogs of taxol. which make the drug easier to administer. Kingston. student Anțony A. Molinero, and senior research scientist A.A. Leslic Gunatilaka received a patent for a method of converting cephalomannine to taxol. Cephalomannine, which is chemically similar to taxol, is also found in the Pacific Ycw. The ability to convert it to taxol increases the supply of that compound. Kingston is also doing research to determine the source of taxol's anticancer activity.

Moisture reduces the Btu content of eoal. Virginia Tech's dewatering process reduces moisture to as little as 1 percent without use of thermal energy. compared 10201040 percent for conventional techniques. The dewatering process, developed by Roe-Hoan Yoon. director of the Virginia Center for Coal and Mincrals Processing, and colleague Gcrald $\boldsymbol{H}$. Luttrell, will

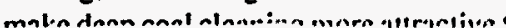

panics trying to mect Clcan Air Act requircments. It may also make the recovery of coal from waste ponds cconomically feasible.

"The commercial utilization of discoveries and inventions has proven to be one of the most efficient and effective ways of disseminating knowledge and technology to the world "outside' academe," said Ted Kohn. intellecual propertics manager at Virginia Tech, ane director of Virginia Tech Intellectual Properties. Inc. (VTIP). "Patent protection of technology provides a competitive cdge and lifts the technology" into that group which is seriously considered for development."

"The signilicant number of students involved in the creation and develonment of these patented technologies is also noteworthy." "suid President Paul Torgersen. "It reflects the close interaction of research and teaching at Virginia Tcch. The lcaming experience of helping in the creation of new knowledge makes these students better prepared and more valuable in their future carcer endeavors and more completcly fulfills the educational mission of the university."

Mike Martin. excculive vice president of VTIP. bclicves that licensing technology from Virginia Tech to businesses in Virginia also helps to creatc jobs and foster economic growth in the commonwealth.
Spivak keynote speaker

For International Week, Global Issues Forum

By. Clara B. Cor

Gayatri Chakravorty Spivak, the Avalon Foundation professor in the humanitics at Columbia University and a lcading postcolonial critic who closcly lollows the lessons of deconstruction, will fill the dual role of keynote speaker for International Weck and speaker for the third Global Issues Forum with an address on April 8. at 6:30 p.m. in Squires Colonial Hall. She will address the topic "Global. Internalional, Transnational."

"Dr. Spivalk is one of the most provocative spcakers on issues dcaling with globalization and multiculturalism. We are fortunate to get her to speak on campus." said Rose-May Guignard. president of the Intemational Club. which is sponsoring the talk with the Council of International Student Organizations in cooperation with the University Officc of International Programs (UOIP). 


\section{Furey, Kajdas patent tribology process}

By Li= Crumbley

An advanced technology for the lubrication of metals and ceramics, developed by Virginia Tech mechanical engineering professor Michael Furey and professor Czeslaw Kajdas of the Warsaw University of Technology, Institute of Chemistry in Poland, has been patented and is in the process of being licensed for commercial applications.

The technology is based on the concept of tribopolymerization first proposed by Furey several years ago and later refined during several years of collaborative research with Kajdas at Virginia Tech. Tribology (from the Greek triko, to rub) is the study of friction, wear, and lubrication. Tribopolymerization is defined as the planned and continuous formation of protective polymeric films directly on rubbing surfaces by the use of sclected monomers capable of forming polymer films "in situ."

Due to the high surface temperatures in regions of contact, and possibly to emission of charged particles, thin polymeric films form in localized areas of greatest wear. These invisible films are continuously formed and replenished only in critical regions of contact and not on other surfaces.

The concept developed by Furey and Kajdas is one of molecular design: it is not

centered on the use of one or only a few compounds, but on classes of specific chemical structures. The process works with a variety of surfaces, including metals and ceramics.

Friction, wear, and lubrication of ccramics is important because ceramics can be used at much higher temperatures than alloy steels commonly used in engines and machines. Ccramics also are harder and more resistant to abrasive or

\section{Corps enrollment increasing}

By Netta S. Smith

The Virginia Tech Corps of Cadets has been making efforts to recruit and keep sludents in the corps, with a goal of building its strength 101,000 cadets by the year 2000 . New scholarships designed to attract outstanding students and a more positive style of training are paying off. Enmllment in this fall's cadet freshman class was up 81 percent over last year's fall numbers.

Recruiting efforts for the cadel class of ' 00 are looking positive. The recruiling team is using the class of 2000 as a springboard 10 produce an increase in visits to the corps. As of Jan. 15, 1996, applications and offers of admission to the Virginia Tech Corps of Cadets were up tremendously from last year's effort. There had been nearly 700 applications (versus 439 at the same point in 1995) and Tech had offered admission to 390 of those applicants. In addition. prospective (Sec CORPS on 8) crosive wear and they cko not corrode. In addilion. some ceramics are much lighter in wcight than conventional steel-base materials.

Examples of the potential uses of ceranics include ceramic engines for higher temperature opcration and greatcr thermodynamic efficicncy. advanced propulsion systems, turbomachincry. gas turbines. acrospace bearings. automotive (See FUREY on \&)

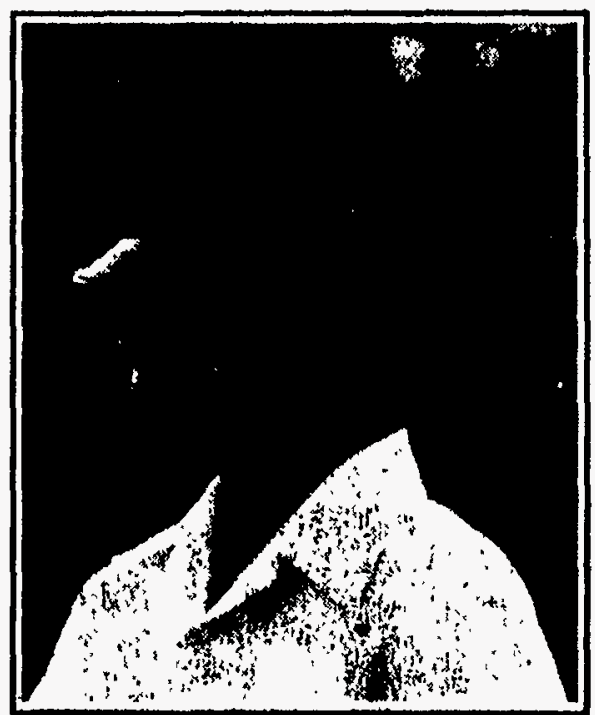

philosopher Jacques Derrida's De la grammutologic. Derrida developed the form of philosophical critique known as deconstruction. which Spivak incorporates. along with feminist and Marxist critiquc. in her work. She has been called one of "the foremost feminist critics who have achicved intemational eminence. and one of the few who can claim to have influenced intcllce tual production on a truly global scale."

Bom in Calcutta Spivak graduated from Presidency College of the University of Calcutta with a first-class honors degree in English. including gold medals for English and Bengali litcrature. After recciving a master's degree in English from Comell and spending a year at Girton College. Cambridge. under a fellowship. she worked as an instructor at the University of lowa while completing her doctoral dissertation on Yeats. She has held visiling university appointments in France. India, and Saudi Arabia and has lectured extensively throughout the world.

In addition to her Derrida translation, (Sce SPIVAK on 7 )

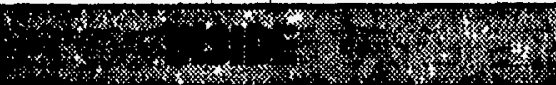

\section{Libraries Offer Current}

Content Search.............. page 3

\section{CIMSS Sponsors}

Tour de Tech page 5 


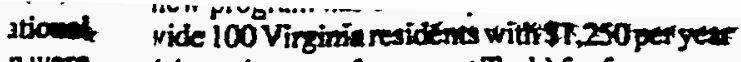
$n$ were (about the cost of 2 rocm at $T$ ech) for four years, ans. earned and 78 Ir state ROTC, I publiations. cations iprove: corps. zase in

to the ini Inc. $990 \mathrm{~s}$, a orps of uitment

aise $\$ 5$ ney also :ruiting, ,et goals an extra VTCCA ie corps,

$s$ of 300 vith stuie corps. students they can rps, and tra effort

icer, the immittee students , current rips. The ed closer Aid. The it making iniversity

fering an adership progresthe corps ollege of 'ollege of liy one of sstamong ntry. This $\imath$ Corps of lleges and te military ective ca-

stablished with the

sizes more e strengths mic excelorps. One then freshit the corps, previously

king to inwithin the sen regular sly column imes. or a total of $\$ 5,000$.

\section{FUREY}

\section{Continued from I}

engine components, cutting and machining of difficult alloys, biomedical (e.g, artificial joints), ceramic heads for magnetic recording, and any perature, abrasive, or corrosive conditions.

Nathan Katz of the U.S. Amny Materiais Laboratory estimates that if such low heat-loss engines were used in diesel engines, the annual fuel savings would exceed $\$ 5$ billion in the U.S. alone. Katz estimates that fuer savings in diesel and gas turbine engines could range from 15 to 40 percent.

A barrier to many commercial uses of ceramics is the fact that conventional lubrication methods, which were developed for steel systems, are often ineffective for ceramic systems.

Earlier research conducted by Furey and Kajdas and funded by the National Science Foundation (NSF) and Virginia's Center for Innovative Technology (CIT) found that compounds selected, developed, or synthesized on the basis of the concept of tribopolymerization are strikingly effective for reducing wear and friction for ceramics.

In the liquid phase, the technology chveloped by Furey and Kajdas brought about wear reductions of $40-80$ percent. In the vapor phase (i.e., in nitrogen), wear reductions with ceramics of up to 99 percent and friction reductions of 40 50 percent were observed. Surprisingly, the additives are more effective at higher temperatures.

In 1995, Furey and Kajdasobtained a patent on tribopolymerization as a method of ceramic lubrication. The researchers recently filed three patent applications for use of the concept with both ceramics and metals.

Also in 1995, the U.S. Government's Energy-Related Inventions Program, a joint program of the Department of Energy and the $\mathrm{Na}$ tional Institute of Standards and Tectnology. selected this invention as one of 12 from over 600 applications as an enabling technology for money bect for the WTA's and moat of the positions." tribological system operating under high temthe development of future high-temperature en- gines. Furey and Kajdas received a $\$ 100,000$ grant from the program to demonstrate the viability of their :-nncept under higher temperatures and loads.

Triad Investors Corp. recently signed agreements with Virginia Tech and the CIT to fund additional research to promote the further development, licensing, and marketing of tribopolymerization as an effective and innovative approach to lubrication. Triad is funding $\$ 100,000$ in research in three areas: Novel fuel lubricity additives for two-stoke engines, tribopolymerization as a novel method of lubricating ceramic machining/cutting tools, and vapor phase lubrication of metals and ceramics at high temperatures by tribopolymerization.

With the support of Triad, other applications of this technology are also being explored, including the area of diesel fuel lubricity-a problem of increasing concern since cleaner low-sulfur fuels have inherently poor lubrication characteristics, leading to excessive fuel pump and injector wear. Stefan Strein, an investment associate for Triad, says, "The Furey/Kajdas technology has great potential for development into viable commercial applications."

Furey and Kajdas met at an intemational conference, after which Kajdas came to Virginia Tech as a visiting professor in 1986. He has returned to carry out joint research with Furey for each of the last 10 summers, as a coinvestigator on research grants from the NSF. Furey and Kajdas have presented papers on this work at intermational tribology conferences in the U.S., Poland, Hungary, Finland, Japan. Australia, and Germany.

Several students have worked with Furey and Kajdas on tribopolymerization research at Virginia Tech, including eight graduate students, a Fulbright scholar from Poland, and five undergraduates, three of whom received summer research fellowships in a program for women and minority engineering students.
The state provides general funds. The miversity has to find money to pay for non-General-Fund expenditures. Shelton said 100 percent of the 208 raises-or $\$ 12.5$ million-comes from general funds, but there is a split in covering the 229 raises. "We have to come up with some nongeneral funds."

Shelton explained that the technology operating funds are used to pay for local-area networks, wide-area networks, client-server projects, and computers for individual faculty members. He pointed out that Virginia Tech is further along in these efforts than the state's other institutions and the $\$ 1,009,000$ per year will go into the university's base budget.

He said the state's rationale for tuming down the request for student financial aid, which did include graduate-student aid, is that since tuition increases are frozen, costs are not going up. That was also the rationale for not approving tuition contracts, Shelton said. According to the handout, "The tuition poljcy for Virginia undergraduates shall be established in the Appropriations Act of 1996-98." A tuition increase may be authorized in the second year for students other than Virginia undergraduates.

The university received $\$ 1.5$ million for enroliment growth and \$1.6 million for inflationary changes for nonpersonal services costs. It is the first time since 1982 the university has received funds for inflationary changes, Shelton said

(To be continued)

\section{TECH}

\section{Continued from 1}

Examples of patents that are being developed locally are those issued to the Fiber and Electro-Optics Research Center faculty and staff members and students. for various sensors and couplers-three of which were awarded in 1995. There are many fiber-optic based businesses in the Blacksburg-Roanoke area, such as Fiber and Sensor Technologies, Inc. of Blacksbure, which is one of the fastest-growing high-tech businesses in Virginia.

Other patents awarded in 1995 for intèllectual properties developed at Virginiz Tech include electrical switches and sensors that use a non-toxic liquid metal, such as for applications that previously used mercury; video instruments to analyze the mineral content of ores and coal; and a wide-scanning spherical antenna.

'This significant increase in VTIP's portfolio of patented technologies augurs well for the continued growth in our licensing and commercialization effort, which for the first time last fiscal year, generated revenues in excess of $\$ 1$ million. In addition to generating supplemental income for the inventors, some of these properties will provide incremental funding of university research," Martin said. "With the continued cooperation and effort of all concemed, the \$2-million milestone is expected to be achieved before the end of the '90s. Virginia Tech-generated technology is also expected to make an ever-increasing contribution to local and state economic development by the start-up of new small technology-based companies." 